\title{
Cytokine Signaling Protein 3 Deficiency in Myeloid Cells Promotes Retinal Degeneration and Angiogenesis through Arginase-1 Up-Regulation in Experimental Autoimmune Uveoretinitis
}

\author{
Mei Chen, Jiawu Zhao, Imran H.A. Ali, Stephen Marry, Josy Augustine, Mohajeet Bhuckory, Aisling Lynch, \\ Adrien Kissenpfennig, and Heping $\mathrm{Xu}$
}

From the Centre for Experimental Medicine, School of Medicine, Dentistry \& Biomedical Science, Queen's University Belfast, Belfast, United Kingdom

\author{
Accepted for publication \\ December 7, 2017. \\ Address correspondence to \\ Heping Xu, M.D., Ph.D., \\ Centre for Experimental Medi- \\ cine, School of Medicine, \\ Dentistry \& Biomedical Sci- \\ ence, Queen's University Bel- \\ fast, 97 Lisburn Rd., Belfast, \\ BT9 7BL, United Kingdom. \\ E-mail: heping.xu@qub.ac.uk.
}

\begin{abstract}
The suppressor of cytokine signaling protein 3 (SOCS3) critically controls immune cell activation, although its role in macrophage polarization and function remains controversial. Using experimental autoimmune uveoretinitis (EAU) as a model, we show that inflammation-mediated retinal degeneration is exaggerated and retinal angiogenesis is accelerated in mice with SOCS3 deficiency in myeloid cells (Lys $\mathrm{M}^{\text {Cre/ }+}{ }^{+} \mathrm{SOCS} 3^{f / f f}$ ). At the acute stage of EAU, the population of infiltrating neutrophils was increased and the population of macrophages decreased in Lys $\mathrm{M}^{\mathrm{Cr} /+} \mathrm{SOCS} 3^{f l / f l}$ mice compared with that in wild-type (WT) mice. Real-time RT-PCR showed that the expression of tumor necrosis factor- $\alpha$, IL-1 $\beta$, interferon- $\gamma$, granulocytemacrophage colony-stimulating factor, and arginase- 1 was significantly higher in the Lys $\mathrm{M}^{\mathrm{Cr} /}{ }^{+} \mathrm{SOCS} 3^{\mathrm{fl} / \mathrm{fl}}$ EAU retina in contrast to the WT EAU retina. The percentage of arginase- $1^{+}$infiltrating cells was significantly higher in the Lys $\mathrm{M}^{\mathrm{Cr} /{ }^{+}} \mathrm{SOCS} 3^{\mathrm{fl} / f l}$ EAU retina than that in the WT EAU retina. In addition, bone marrow-derived macrophages and neutrophils from the Lys ${ }^{\mathrm{Cre} /+} \mathrm{SOCS} 3^{f l f l}$ mice express significantly higher levels of chemokine (C-C motif) ligand 2 and arginase- 1 compared with those from WT mice. Inhibition of arginase using an L-arginine analog amino-2-borono-6-hexanoic suppressed inflammationinduced retinal angiogenesis without affecting the severity of inflammation. Our results suggest that SOCS3 critically controls the phenotype and function of macrophages and neutrophils under inflammatory conditions and loss of SOCS3 promotes the angiogenic phenotype of the cells through up-regulation of arginase-1. (Am J Pathol 2018, 188: 1007-1020; https://doi.org/10.1016/j.ajpath.2017.12.021)
\end{abstract}

Inflammation-induced angiogenesis is involved in many pathological conditions, including cancer and autoimmune diseases. ${ }^{1-3}$ Although the management of angiogenic diseases has been revolutionized during the past decade with the use of vascular endothelial growth factor (VEGF) inhibitors, ${ }^{4-6}$ they remain a major challenge in modern medical care. Previously, we reported that chronic inflammation in experimental autoimmune uveoretinitis (EAU) induces retinal angiogenesis, ${ }^{7}$ a condition that mirrors retinal neovascular membrane (RNM) secondary to long-standing posterior segment intraocular inflammation $^{8}$ or retinal angiomatous proliferation in agerelated macular degeneration. ${ }^{9}$ It was further shown that $\mathrm{CCR}^{+}{ }^{+}$macrophages are critically involved in EAU-induced retinal angiogenesis, ${ }^{7,10}$ although the underlying mechanism remains poorly defined.

The EAU retina is characterized by a diverse immune cell infiltrate, including macrophages, neutrophils, dendritic cells (DCs), CD4 and CD8 T cells, B cells, and myeloidderived suppressor cells (MDSCs). ${ }^{10}$ The constitution of different subsets of infiltrating cells differs at different stages of EAU. For example, macrophages and neutrophils

Supported by National Eye Research Centre grant SCAID061 (H.X.) and Fight for Sight grant 1361/2 (H.X. and M.C.).

M.C. and J.Z. contributed equally to this work.

Disclosures: None declared. 
constitute $40 \%$ and $10 \%$ of retinal infiltrating cells during acute EAU [ie, day 25 post immunization (p.i.)] and are reduced to $19 \%$ and $1 \%$, respectively, during latter chronic stages of EAU. ${ }^{10}$ On the other hand, the percentage of CD8 T cells, CD11c DCs, and MDSCs increased from the acute stage to the chronic stage ${ }^{10}$ Furthermore, a dynamic change in the phenotype of the infiltrating cells in different stages of EAU was also observed. For instance, most macrophages were found to be $\mathrm{CD}^{+} 8^{+}$(proinflammatory phenotype) during the acute stages, whereas at the chronic (angiogenic) stages, more than half of the infiltrating F4/80 macrophages were found to be arginase-1 (Arg-1) positive (wound-healing phenotype). ${ }^{7}$ These results suggest that the microenvironment of the inflamed retina not only controls the type of circulating immune cells to be recruited but also determines the phenotype and function of infiltrating cells.

Chemokine (C-C motif) ligand 2 (CCL2)/CCR2 but not CX3CL1/CX3CR1 pathway is critically involved in the trafficking of monocytes across the blood retinal barrier in EAU, ${ }^{11}$ although in the absence of the CCL2/CCR2 pathway, neutrophils can infiltrate the retina and induce inflammation. In the inflamed retina, infiltrating immune cells respond to environmental cues through cell surface receptors and differentiate into different types of effector cells. The JAK/ STAT pathways are critically involved in many cytokine receptor signaling cascades. ${ }^{12}$ Although there are only four known JAKs and seven STATs, collectively they control $>40$ cytokine receptor signaling. ${ }^{12,13}$ The JAK1,2/STAT3 is known to be important for the transduction and transcription of cytokines involved in proliferation and angiogenesis, such as IL-6, VEGF, epidermal growth factors, and granulocytemacrophage colony-stimulating factor (GM-CSF). ${ }^{12,14,15}$ The SOCS proteins negatively regulate the JAK/STAT pathways through association with key phosphorylated tyrosine residues on JAK and/or cytokine receptors. ${ }^{16}$ SOCS3 critically control the JAK1,2/STAT3 pathway. ${ }^{17-19}$ The role of SOCS3 in macrophage polarization and function remains controversial. ${ }^{20,21}$

This study aimed to understand the role of SOCS3 in myeloid cell activation and function in the context of EAU. We show that EAU-induced retinal degeneration was exaggerated and angiogenesis was accelerated in the myeloid cell-specific SOCS3-deficient mice (ie, LysM ${ }^{\mathrm{Cre} /+} \mathrm{SOCS}_{3}{ }^{\mathrm{f} / \mathrm{fl}}$ mice). Further mechanistic studies highlighted that deletion of SOCS3 led to increased Arg-1 and CCL2 expression in both macrophages and neutrophils.

\section{Materials and Methods}

\section{Mice and Induction of EAU}

Eight- to 12 -week-old $\mathrm{C} 57 \mathrm{BL} / 6 \mathrm{~J}, \quad \mathrm{SOCS} 3^{\text {flft }}$ and $\mathrm{LysM}^{\mathrm{Cre} /+} \mathrm{SOCS}^{\text {fl/fl}}$ mice (both in C57BL/6J background) were used in the study. The LysM ${ }^{\mathrm{Cre} /+} \mathrm{SOCS}^{\mathrm{fl} / f l}$ mice were obtained by crossbreeding the $\operatorname{SOCS} 3^{f / A l}$ mice and the LysM-Cre mice. The absence of SOCS3 in myeloid cells in the $\mathrm{LysM}^{\mathrm{Cre} / \mathrm{SOCCS}} 3^{\mathrm{Al} / \mathrm{f}}$ mice was confirmed by Western blotting of peritoneal macrophages. The $\mathrm{SOCS}^{f / f t}$ mice were used as controls in some experiments. All mice were maintained in the Biological Research Unit at Queen's University Belfast and exposed to a 12-hour light/night cycle with free access to water and food. All procedures were conducted under the regulation of the UK Home Office Animals (Scientific Procedures) Act 1986 and approved by the Animal Welfare \& Ethical Review Body of Queen's University Belfast.

EAU was induced in mice using a protocol described previously. ${ }^{22,23}$ Briefly, mice were immunized with $500 \mu \mathrm{g}$ of IRBP $_{1-20}$ (GPTHLFQPSLVLDMAKVLLD, GL Biochem, Shanghai, China), emulsified 1:1 in complete Freund's adjuvant (Difco Laboratories, Detroit, MI), and supplemented with $2.5 \mathrm{mg} / \mathrm{mL}$ of Mycobacterium tuberculosis H37Ra (Difco Laboratories). An additional $1 \mu \mathrm{g}$ of Bordetella pertussis toxin (Tocris Bioscience, Bristol, UK) was administered intraperitoneally immediately after immunization injection.

\section{Clinical Assessment of Retinal Inflammation}

Retinal inflammation was assessed clinically at different days p.i. by the Topical Endoscopic Fundus Imaging system and scored using the criteria described previously. ${ }^{24}$ The animals were anaesthetized using isoflurane (Merial Animal Health Ltd., Essex, UK), and pupils were dilated with $1 \%$ atropine sulfate and $2.5 \%$ phenylephrine hydrochloride (Chauvin, Essex, UK). Fundus images were captured by Nikon D90 camera via an endoscope and saved in TIF format. The inflammation score is based on i) the number and size of retinal infiltrates, ii) the severity of optic disk swelling, and iii) the severity and number of vascular cuffing. ${ }^{24}$ The structural damage score is based on the area of retinal lesion or atrophy and the number of linear lesion. ${ }^{24}$ Inflammation and structure damage scores were analyzed separately.

Fundus fluorescein angiography (FFA) was conducted by i.p. injection of $100 \mu \mathrm{L}$ of $10 \%$ sodium fluorescein to mice. The FFA images were recorded within 5 minutes using the Spectralis HRA2 confocal scanning laser ophthalmoscope (Heidelberg Engineering Ltd., Hertfordshire, UK). Four images were taken from different regions of the fundus in each eye. The number of localized hyperfluorescence lesions in each eye was manually counted using the FFA images.

\section{SD-OCT Imaging}

Mice were anaesthetized with ketamine (Vetoquinol UK Ltd., Buckingham, UK) and xylazine (Rompun; Bayer Health Care, Kiel, Germany) via i.p. injection. Pupils were dilated as described above. Liquid gel eye drops (Viscotears; Novartis Pharmaceuticals Ltd., Surrey, UK) was used to moisten the ocular surface. OCT scans $\left(30^{\circ}\right.$ field of view) were conducted using the spectral domain-optical coherence tomography 
Table 1 Antibodies Used in Flow Cytometry

\begin{tabular}{lllll}
\hline Target molecule & Conjugated fluorochrome & Origin & Clone & Company \\
\hline CCR2 & APC & Rat & 475301 & R\&D Systems \\
CD8a & APC-Cy7 & Rat & $53-6.7$ & BD Biosciences \\
Ly6G & APC-Cy7 & Rat & BD Biosciences \\
CX CR1 & Alexa Fluor 488 & Goat & (Polyclonal) & R\&D Systems \\
CD4 & Pacific blue & Rat & RM4-5 & BD Biosciences \\
I/A I/E & eF450 & Rat & M5/114.15.2 & eBiosciences \\
F4/80 & PE & Rat & CI:A3-1 & Serotec \\
Gr-1 & PE & Rat & RB6-8C5 Biosciences \\
CD11C & PE & Hamster & HL3 & BD Biosciences \\
CD86 & PE & Rat & GL1 & BD Biosciences \\
CD11b & PE-Cy7 & Rat & M1/70 & BD Biosciences \\
CD45 & PerCP & Rat & $30-F 11$ & BD Biosciences \\
\hline
\end{tabular}

$\mathrm{APC}$, allophycocyanin; $\mathrm{PE}$, phycoerythrin; PerCP, peridinin chlorophyll protein complex.

(SD-OCT) system (Heidelberg Engineering Ltd., Hertfordshire, UK). Neuroretinal thickness (from nerve fiber layer to retinal pigment epithelium) was measured $1000 \mu \mathrm{m}$ away from the optic disk at four quadrants.

\section{In Vivo Treatment}

Wild-type (WT) EAU mice were administered intraperitoneally with the Arg inhibitor amino-2-borono-6-hexanoic acid (ABH, $200 \mu \mathrm{mol} / \mathrm{L}$; Cayman Chemical Company, Ann Arbor, MI) once daily from day 60 to day 79 p.i. The LysM $^{\text {Cre/+}}{ }^{\text {SOCS3 }}{ }^{f / f l}$ EAU mice were treated with $200 \mu \mathrm{M}$ $\mathrm{ABH}$ from day 14 to day 59 p.i. Clinical and histologic examination was conducted at the end of treatment. The control EAU group received $100 \mu \mathrm{L}$ of phosphate-buffered saline (PBS) injections.

\section{Histopathologic Analysis}

Mouse eyes were fixed in 2.5\% (w/v) glutaraldehyde (Agar Scientific Ltd., Stansted, UK) for 24 hours then embedded in paraffin and processed for hematoxylin and eosin staining. Sections from four layers, $100 \mu \mathrm{m}$ apart, were studied in each eye, and the severity of EAU was graded according to the criteria described previously. ${ }^{25}$

\section{Immunofluorescence of Retinal Whole Mounts or Sections}

Mouse eyes were fixed with $2 \%$ paraformaldehyde (Agar Scientific Ltd.) at room temperature for 2 hours. The retinas were dissected and permeabilized with $0.3 \%$ Triton $\mathrm{X}-100$ (Sigma-Aldrich, Dorset, UK) in PBS for 6 hours. The samples were then incubated with rabbit anti-mouse collagen IV (AbD Serotec, Kidlington, UK) or rat anti-mouse CD45 (BD Biosciences, Oxford, UK) and rabbit anti-Arg-1 (Santa Cruz, Heidelberg, Germany) at $4^{\circ} \mathrm{C}$ overnight, followed by incubating with Alexa Fluor 546-conjugated donkey anti-rabbit IgG or Alexa Fluo 488-conjugated donkey anti-rat IgG (Life Technologies Ltd, Paisley, UK) for 3 hours. After thorough washes, samples were mounted on glass slides with Vectashield mounting medium (Vector Laboratories, Burlingame, CA).

Retinal cryosections (6 $\mu \mathrm{m}$ thick) were fixed with $2 \%$ paraformaldehyde for 30 minutes. Samples were blocked with $10 \%$ bovine serum albumin, followed by incubation with anti-mouse collagen IV (AbD Serotec) and rat antimouse CD105 (Bio-Red Laboratories Led, Watford, UK) for 2 hours. After thorough washes, samples were incubated with Alexa Fluor 488-conjugated donkey anti-rabbit IgG and Alexa Fluor 546-conjugated goat anti-rat IgG (Life Technologies Ltd.) for 1 hour. All samples were examined by confocal microscopy (Eclipse TE200-U, Nikon UK Ltd, Surry, UK).

\section{Cell Culture}

\section{BMDMs}

Bone marrows were flushed from the tibia and femur of WT and $\mathrm{LysM}^{\mathrm{Cre} /+} \mathrm{SOCS}^{\text {fl/fl }}$ mice. Red blood cells were removed with lysis buffer. The cells were then cultured in Dulbecco's modified Eagle's medium (Gibco BRL, Paisley, UK) supplemented with $10 \%$ fetal calf serum and 15\% L929 conditioned medium and $100 \mu \mathrm{g} / \mathrm{mL}$ of an antimicrobial for primary cells (Primocin; InvivoGen, San Diego, CA) at $37^{\circ} \mathrm{C}$ for 7 days. The bone marrow-derived macrophages (BMDMs) were harvested, and the phenotype confirmed by flow cytometry $\left(>95 \% \mathrm{CD} 1 \mathrm{~b}^{+} \mathrm{F} 4 / 80^{+}\right)$. The BMDMs were further stimulated overnight with $100 \mathrm{ng} / \mathrm{mL}$ of interferon (IFN) $-\gamma$ (R\&D Systems, Abingdon, UK) plus 50 $\mathrm{ng} / \mathrm{mL}$ of lipopolysaccharide (LPS) (Sigma-Aldrich) for M1 activation or with $20 \mathrm{ng} / \mathrm{mL}$ of IL-4 (R\&D Systems) for M2 activation. $^{26}$

\section{Bone Marrow Neutrophils}

Neutrophils were purified from the bone marrow of $\mathrm{SOCS}^{f / f l}$ and $\mathrm{LysM}^{\mathrm{Cre} /+} \mathrm{SOCS}^{f / f l}$ mice using a neutrophil isolation kit (Miltenyi Biotec, Bisley, UK) and confirmed to be $>90 \% \mathrm{Ly} 6 \mathrm{G}^{+}$. Total RNAs were isolated from the cells and further processed for real-time RT-PCR analysis of immune-related genes. 
Table 2 Primers Used in Real-Time RT-PCR

\begin{tabular}{|c|c|c|c|}
\hline Targets & Annealing temperature $\left({ }^{\circ} \mathrm{C}\right)$ & Sequences & \\
\hline \multirow[t]{2}{*}{$18 \mathrm{~S}$} & 58 & Forward & $5^{\prime}-$ AGGGGAGAGCGGGTAAGAGA $-3^{\prime}$ \\
\hline & & Reverse & $5^{\prime}$-GGACAGGACTAGGCGGAACA-3' \\
\hline \multirow[t]{2}{*}{ Arg-1 } & 61 & Forward & 5'-TTATCGGAGCGCCTTTCTCAA-3' \\
\hline & & Reverse & 5'-TGGTCTCTCACGTCATACTCTGT-3' \\
\hline \multirow[t]{2}{*}{ CCL2 } & 58 & Forward & 5'-AGGTCCCTGTCATGCTTCTG-3' \\
\hline & & Reverse & 5'-TCTGGACCCATTCСTTCTTG-3' \\
\hline \multirow[t]{2}{*}{ IFN- $\gamma$} & 56 & Forward & $5^{\prime}$-GCTCTGAGACAATGAACGCT-3' \\
\hline & & Reverse & 5'-AAAGAGATAATCTGGCTCTGC-3' \\
\hline \multirow[t]{2}{*}{ IL-1 $\beta$} & 58 & Forward & 5'-TCCTTGTGCAAGTGTCTGAAGC-3' \\
\hline & & Reverse & 5'-ATGAGTGATACTGCCTGCCTGA-3' \\
\hline IL-10 & 58 & Forward & 5'-TGCAGGACTTTAAGGGTTACTTGG-3' \\
\hline & & Reverse & 5'-TCGCTCAAGTTCAGCTTGGT-3' \\
\hline \multirow[t]{2}{*}{ TNF- $\alpha$} & 58 & Forward & 5'-GCСTCTTCTCATTCCTGCTT-3' \\
\hline & & Reverse & 5'-CTCCTCCACTTGGTGGTTTG-3' \\
\hline \multirow[t]{2}{*}{ VEGF- $\alpha$} & 58 & Forward & 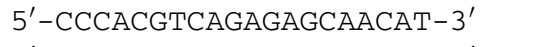 \\
\hline & & Reverse & 5'-TTTCTTGCGCTTTCGTTTTT-3' \\
\hline \multirow[t]{2}{*}{ Ym-1 } & 58 & Forward & 5'-АСTTTGATGGCCTCAACCTG-3' \\
\hline & & Reverse & 5'-АATGATTCCTGCTCCTGTGG-3' \\
\hline \multirow[t]{2}{*}{ TGF- $\beta$} & 58 & Forward & 5'-GTGTGGAGCAACATGTGGAACT-3' \\
\hline & & Reverse & 5'-GGGCTGATCCCGTTGATTTC-3' \\
\hline IL-17a $\left(I l 17 a^{*}\right)$ & & & Mm00439618_m $1^{\dagger}$ \\
\hline GM-CSF (Csf2*) & & & Mm01290062_m1 $1^{\dagger}$ \\
\hline
\end{tabular}

*Gene expression was conducted using the LightCycler 480 Probe Master from Roche Diagnostics GmbH.

${ }^{\dagger}$ Accessible at $h t t p: / / w w w$. thermofisher.com/order/genome-database.

Arg-1, arginase-1; CCL2, chemokine (C-C motif) ligand 2; GM-CSF, granulocyte-macrophage colony-stimulating factor; IFN- $\gamma$, interferon $\gamma$; iNOS, inducible nitric oxide synthase; TGF- $\beta$, transforming growth factor $\beta$; TNF- $\alpha$, tumor necrosis factor $\alpha$; VEGF- $\alpha$, vascular endothelial growth factor $\alpha$; Ym- 1 , chitinase-like 3 .

\section{Neutrophil Oxidative Burst Assay}

Fresh isolated bone marrow neutrophils $\left(1 \times 10^{5}\right)$ from WT and LysM-Cre:SOCS3 ${ }^{f l f t}$ mice were mixed with $50 \mu \mathrm{g} / \mathrm{mL}$ of dihydrorhodamine 123 (Life Technologies) in $200 \mu \mathrm{L}$ of RPMI 1640 medium supplemented with $10 \%$ fetal calf serum and 100 $\mu \mathrm{g} / \mathrm{mL}$ of an antimicrobial for primary cells (Primocin; InvivoGen) in FACS tubes at $37^{\circ} \mathrm{C}$ for 20 minutes. The reaction was stopped by cooling samples on ice for 10 minutes. Rhodamine generated from dihydrorhodamine 123 by reactive oxygen species was examined by flow cytometry (BD FACSCantoII, BD Biosciences). The data were analyzed by FlowJo software version 10.0.7 (TreeStar Inc., Ashland, OR).

\section{Neutrophil Phagocytosis Assay}

Fresh isolated bone marrow neutrophils $\left(5 \times 10^{4}\right)$ were mixed with $1 \times 10^{6}$ fluorescein isothiocyanate-conjugated Escherichia coli particles in $1 \mathrm{~mL}$ of RPMI 1640 medium supplemented with $10 \%$ fetal calf serum and $100 \mu \mathrm{g} / \mathrm{mL}$ of an antimicrobial for primary cells (Primocin; InvivoGen) in FACS tubes and incubated at $37^{\circ} \mathrm{C}$ for 2 hours or 24 hours.
Samples were rapidly chilled on ice, and free E. coli particles were washed away by ice-cold PBS. Samples incubated at $4^{\circ} \mathrm{C}$ were used as background controls. Samples were examined by BD FACSCantoII (BD Biosciences). The data were analyzed by FlowJo software (TreeStar Inc.).

\section{Flow Cytometry}

\section{Retinal Single-Cell Preparation}

The retinas were dissected and treated with $1 \mathrm{mg} / \mathrm{mL}$ of collagenase I (Sigma-Aldrich) at $37^{\circ} \mathrm{C}$ for 30 minutes. The single-cell suspension was washed and filtered through a $100-\mu \mathrm{m}$ cell strainer (BD Biosciences). The cell suspension from one retina was used for each flow cytometry analysis.

\section{Preparation of Cells from Blood and Spleen}

Mouse whole blood was collected in heparinized tubes, and 30 $\mu \mathrm{L}$ was used for FACS staining. The spleen was homogenized, and single-cell suspension was obtained by passing samples through a $100-\mu \mathrm{m}$ cell strainer (BD Labware, Oxford, UK). Red blood cells were removed with lysis buffer, and $2 \times 10^{5}$ splenocytes were used for FACS staining. 

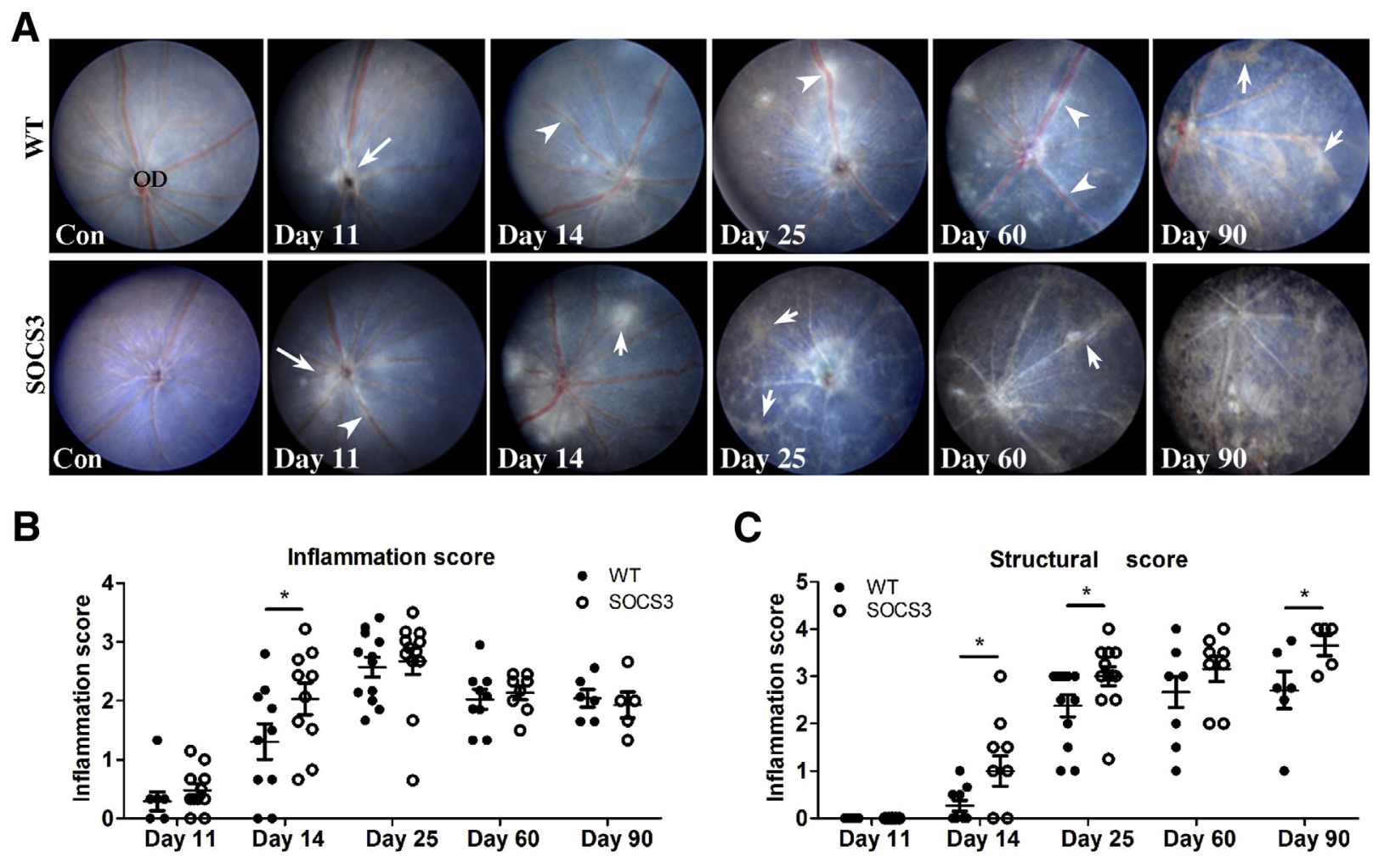

C

D
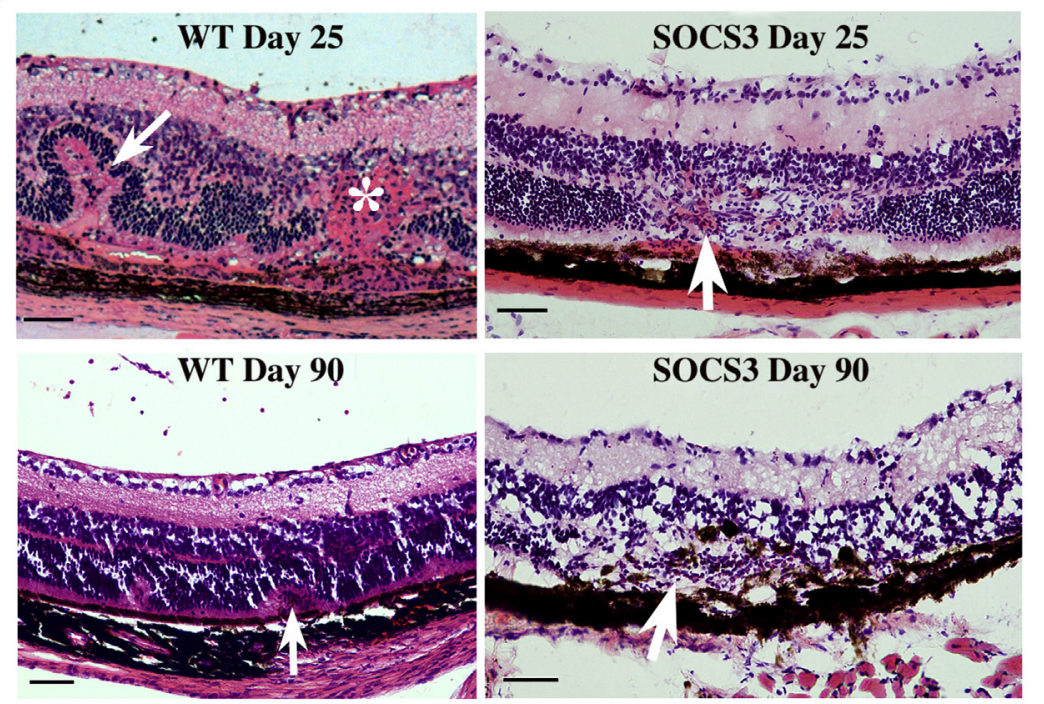
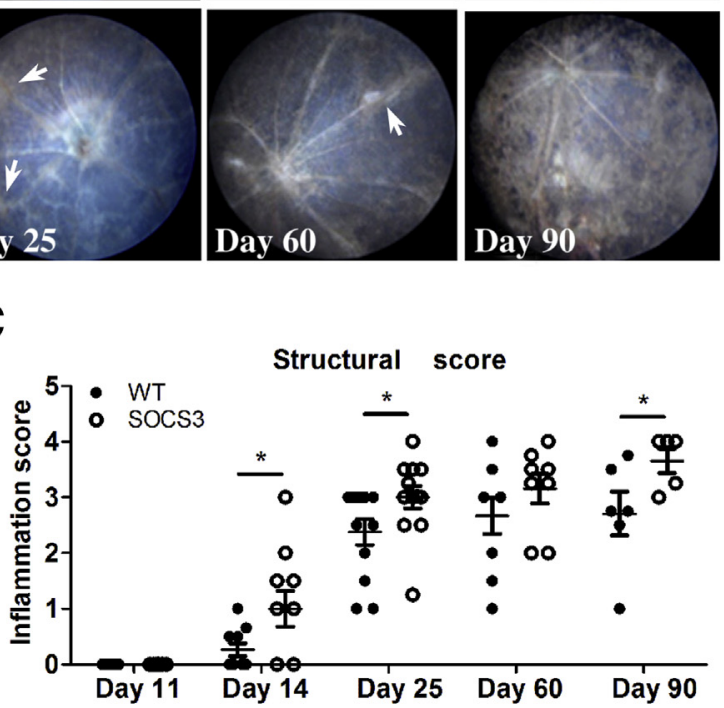

Structural score

$\mathbf{E}$

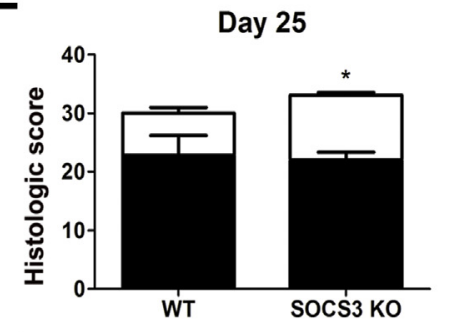

$\mathbf{F}$

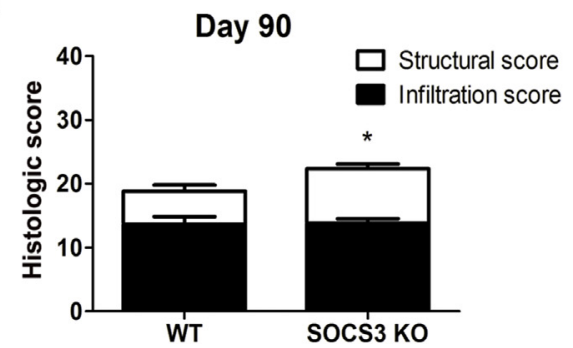

Figure 1 Retinal inflammation in wild-type (WT) and myeloid cell-specific suppressor of cytokine signaling protein 3 (SOCS3)-deficient (LysM ${ }^{\text {cre/+ }}$ SOCS ${ }^{f / f l}$ ) experimental autoimmune uveoretinitis (EAU) mice. EAU was induced in WT and LysM ${ }^{\mathrm{Cre} /+}{ }^{+} \mathrm{SOCS} 3^{f l f f}$ mice, and clinical inflammation was examined by fundus imaging at different days after immunization. Histologic examination was conducted on days 25 and 90 post immunization (p.i.). A: Fundus images from WT and LysM ${ }^{\mathrm{Cre} /+} \mathrm{SOCS} 3^{f / f l}$ mice on different p.i. days (day 11, day 14, day 25, day 60, and day 90). Arrows indicate retinal infiltrates; arrowheads, vascular cuffings. B: Clinical score of retinal inflammation. C: Clinical score of retinal structure damage at different stages of EAU. D: Representative images of hematoxylin and eosin staining of EAU retina from WT and LysM ${ }^{\text {Cre/ }}{ }^{+}$SOCS $33^{f l f l}$ mice. Arrows indicate retinal folds (WT panels) and fibrotic lesions (SOCS3 panels); and asterisk, granular lesion. E and F: Histologic scores on retinal immune cell infiltration and structure damage in WT and LysM ${ }^{\text {Cre/ }}+S_{0 C S}{ }^{f l f l}$ EAU mice. $n=6$ to $12(\mathbf{A}-\mathbf{C}) ; n=6(\mathbf{D}-\mathbf{F}) .{ }^{*} P<0.05$ versus WT mice (Mann-Whitney test). Scale bars $=50 \mu \mathrm{m}$. Con, control; K0, knockout; 0D, optic disk.

Preparation of Cells from in Vitro Cultures

The cells were dissociated by incubation in cold PBS followed by scraping and flushing. Cell aggregates were dissociated, and single-cell suspension was obtained by passing the samples through a cell strainer $(100 \mu \mathrm{m})$. A total of $2 \times 10^{5}$ cells were used for each FACS staining. 
FACS Staining, Acquisition, and Analysis

After blocking the $\mathrm{Fc} \gamma$ receptor with anti-mouse CD16/ CD32 (2.4G2, BD Biosciences) for 15 minutes, the cells were incubated with fluorochrome-conjugated antibody cocktail (Table 1) for 30 minutes on the ice. The samples were washed and resuspended in $200 \mu \mathrm{L}$ of FACS buffer and processed for FACS analysis using the FACS CantoII (BD Biosciences). All data were analyzed using FlowJo software (TreeStar Inc.). The gating strategy to detect retinal infiltrating immune cells is detailed in our previous publication. ${ }^{10}$

\section{Real-Time RT-PCR}

The RNeasy Mini Kit (Qiagen, West Sussex, UK) and the TRI Reagent (Sigma-Aldrich) were used to extract total RNA from retinal tissue and cell cultures, respectively. The same amount of total RNA was used for reverse transcription using the SuperScript II Reverse Transcriptase kit (Invitrogen, Paisley, UK) according to the manufacturer's instructions. The mRNA expression levels of different genes were quantified by the real-time RT-PCR using the LightCycler 480 system with SYBR Green I Master (Roche Diagnostics $\mathrm{GmbH}$, Mannheim, Germany). The primers used are listed in Table 2. 18S was used as a housekeeping gene. Murine IL17a and GM-CSF mRNA expression levels were determined with LightCycler 480 Probe Master (Roche Diagnostics GmbH). The assay systems (Mm00439618_m1, Mm01290062_m1) were purchased from Thermo Fisher Scientific (Loughborough, UK).

\section{Measurement of Cytokine and Nitric 0xide}

Cytokines TNF- $\alpha$, IL-6, IFN- $\gamma$, IL-10, and CCL2 in the supernatants of BMDMs were analyzed using cytometric bead array assay (BD Biosciences) according to the manufacturer's instructions. VEGF-A was measured using the DuoSet enzyme-linked immunosorbent assay kit (R\&D Systems). Nitric oxide production in the supernatant was assessed using the Griess Reagent Kit (Life Technologies).

\section{Statistical Analysis}

All clinical and histologic scores were independently graded by two researchers (J.Z. and S.M.), and the means of the 2 scores were used as the final scores for statistical analysis. EAU clinical and histologic scores were analyzed by the Mann-Whitney $U$-test. Retinal whole-mount and cell culture data were analyzed by the $t$-test. Retinal immune cell infiltration and gene expression at different time points in WT and $\mathrm{LysM}^{\mathrm{Cre} /+} \mathrm{SOCS} 3^{f l f l}$ mice were analyzed by two-way analysis of variance. All data were presented as means \pm SEM. $P$ $<0.05$ was considered as statistically significant.

\section{Results}

Retinal Inflammation and Degeneration in LysM $^{\text {Cre/+}}{ }^{+}$SOCS3 $^{f l f l}$ EAU Mice

Early retinal inflammation was observed at day 11 p.i. in both WT and $\mathrm{LysM}^{\mathrm{Cre} /+} \mathrm{SOCS} 3^{\mathrm{flfl}}$ mice, characterized by swelling of the optic disk and vascular cuffing (Figure 1A). The severity of inflammation was increased at day 14, reached peak at day 25 p.i., and then decreased slightly at days 60 and 90 p.i. (Figure 1 , $\mathrm{A}$ and B). Inflammatory scores of the $\mathrm{LysM}^{\mathrm{Cre} /+} \mathrm{SOCS}^{\mathrm{fl} / \mathrm{fl}}$ mice were significantly higher than those of WT mice at day 14 p.i. but not at later time points (Figure 1B). Interestingly, the structural damage characterized by linear lesions (Figure 1A) and retinal atrophy (Figure 1, A and C) was more severe in $\mathrm{LysM}^{\mathrm{Cre} / \mathrm{S}} \mathrm{SOCS}^{\mathrm{Alfl}}$ EAU mice than that in WT EAU mice. A repeated study using C57BL/6 WT, SOCS3 ${ }^{f l f t}$, and $\mathrm{LysM}^{\mathrm{Cre} /+} \mathrm{SOCS}^{\mathrm{fl} / \mathrm{fl}}$ mice confirmed that the $\mathrm{LysM}^{\mathrm{Cre} /+} \mathrm{SOCS}^{\mathrm{fl} / \mathrm{fl}}$ mice suffered from more severe EAUmediated retinal damage compared with WT mice, and there was no difference between SOCS3 $3^{f / A l}$ and WT EAU mice (Supplemental Figure S1).

Retinal degeneration was further confirmed by SD-OCT examination. The thickness of neuroretina was comparable in nonimmunized WT and $\mathrm{LysM}^{\mathrm{Cre} /+} \mathrm{SOCS} 3^{f / / l}$ mice. After EAU induction, although the thickness was progressively reduced in both WT and $\mathrm{LysM}^{\mathrm{Cre} /+} \mathrm{SOCS} 3^{\mathrm{flfl}}$ mice, the reduction was more pronounced in the $\mathrm{LysM}^{\mathrm{Cre} /+} \mathrm{SOCS}^{\text {flfl }}$ EAU mice, particularly at day 25 p.i. (Supplemental Figure S2).

Histologic examination showed that cell infiltration in $\mathrm{WT}$ and $\mathrm{LysM}^{\mathrm{Cre} /+} \mathrm{SOCS}^{\text {fl/f }}$ mice at day 25 and day 90 p.i. was comparable (Figure 1, D and E). However, the $\mathrm{LysM}^{\mathrm{Cre} /+} \mathrm{SOCS}^{\text {flffl}}$ EAU mice had higher levels of structural damage, characterized by the disappearance of photoreceptors, disarrangement of retinal layers, and appearance of subretinal/intraretinal scars compared with WT EAU mice (Figure 1, D and E). Taken together, these results suggest that deletion of SOCS3 in myeloid cells resulted in severe retinal degeneration in our model of EAU.

\section{Early Onset of Retinal Angiogenesis in LysM $^{\text {Cre/+}}{ }^{\text {SOCS3 }}{ }^{f / f l}$ EAU Mice}

FFA showed normal retinal vasculature in nonimmunized WT and $\mathrm{LysM}^{\mathrm{Cre} /+} \mathrm{SOCS} 3^{\mathrm{flfl}}$ mice (Figure 2A). Small patches of hyperfluorescein lesions (an indication of localized severe vascular abnormality) were observed at day 60 p.i. WT mice. However, in LysM ${ }^{\mathrm{Cre} /+} \mathrm{SOCS}^{f / f f}$ EAU mice, similar lesions were observed as early as at day 25 p.i. (Figure 2A). The number and size of the lesion increased as the disease progressed in both WT and $\mathrm{LysM}^{\mathrm{Cre} /+} \mathrm{SOCS}^{\text {fl/fl }}$ mice (Figure 2, A and B). Significantly more lesions were observed in $\mathrm{LysM}^{\mathrm{Cre} /+}$ SOCS $3^{f / f l}$ EAU mice at day 60 and 90 p.i. compared with WT EAU mice (Figure 2, A and B).

Confocal microscopy of retinal flat mounts detected patches of collagen $\mathrm{IV}^{+}$lesions that contain area of diffuse 

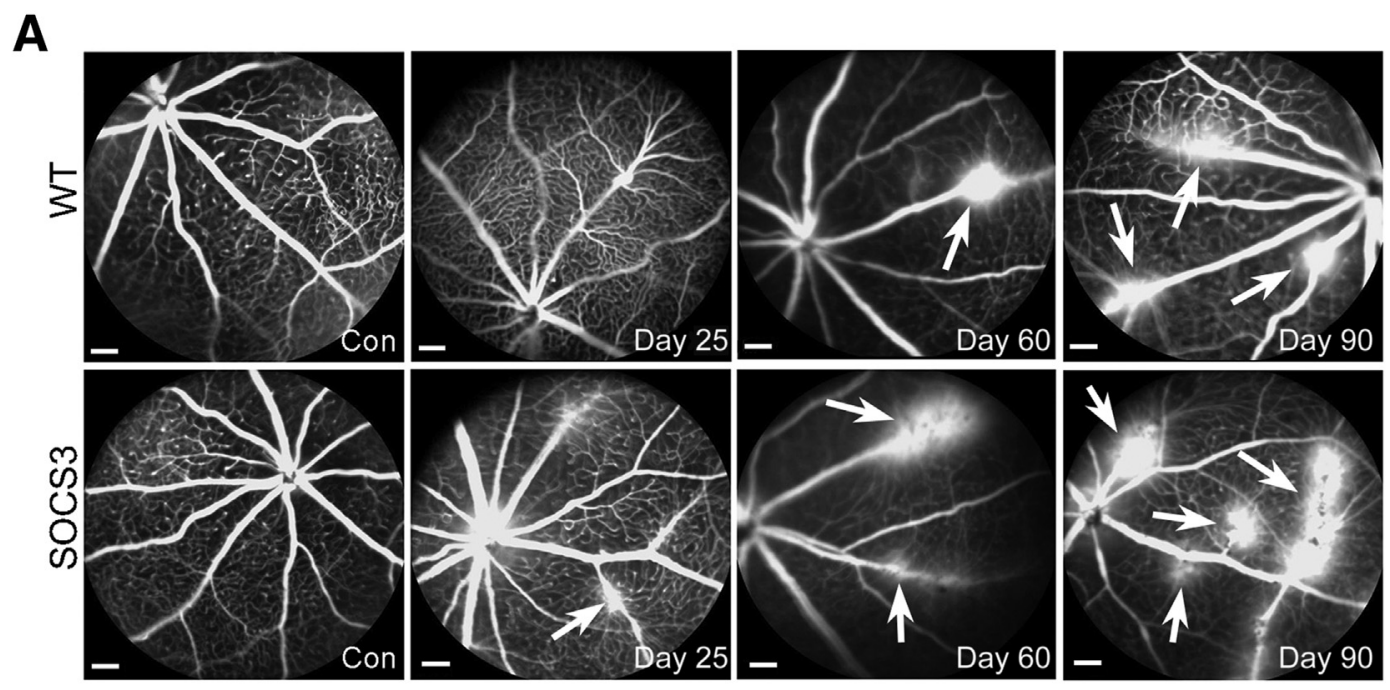

B

C
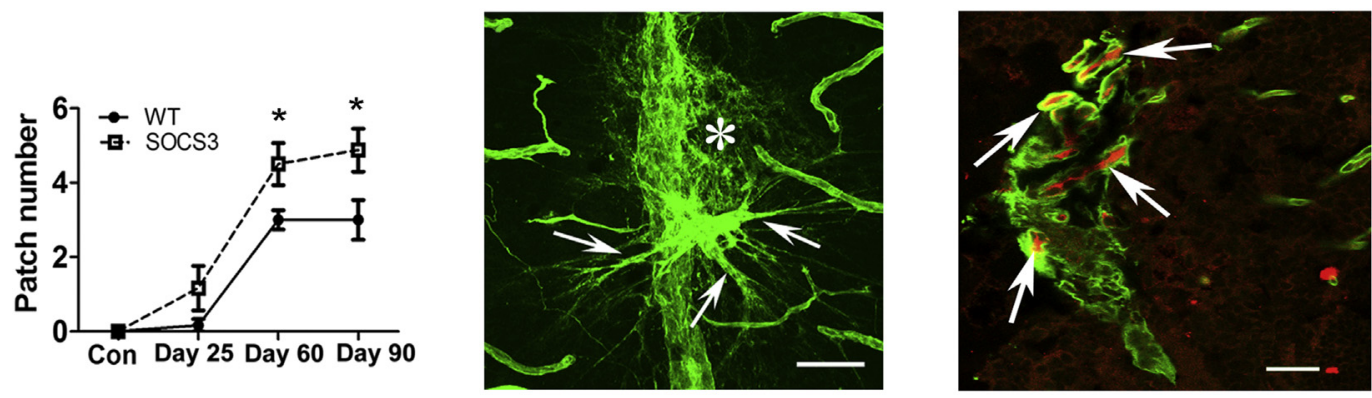

E
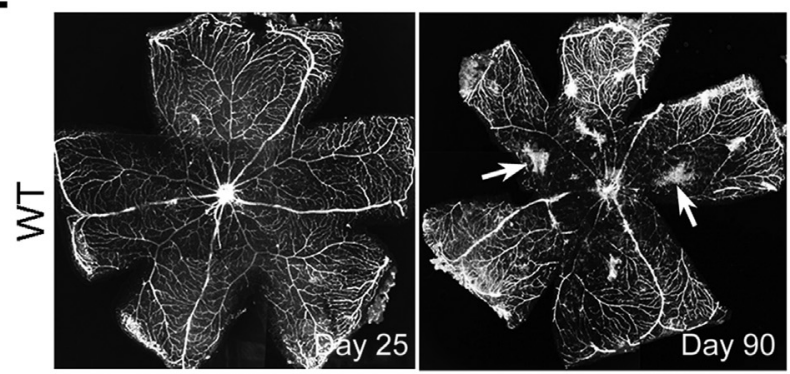

$\mathbf{F}$
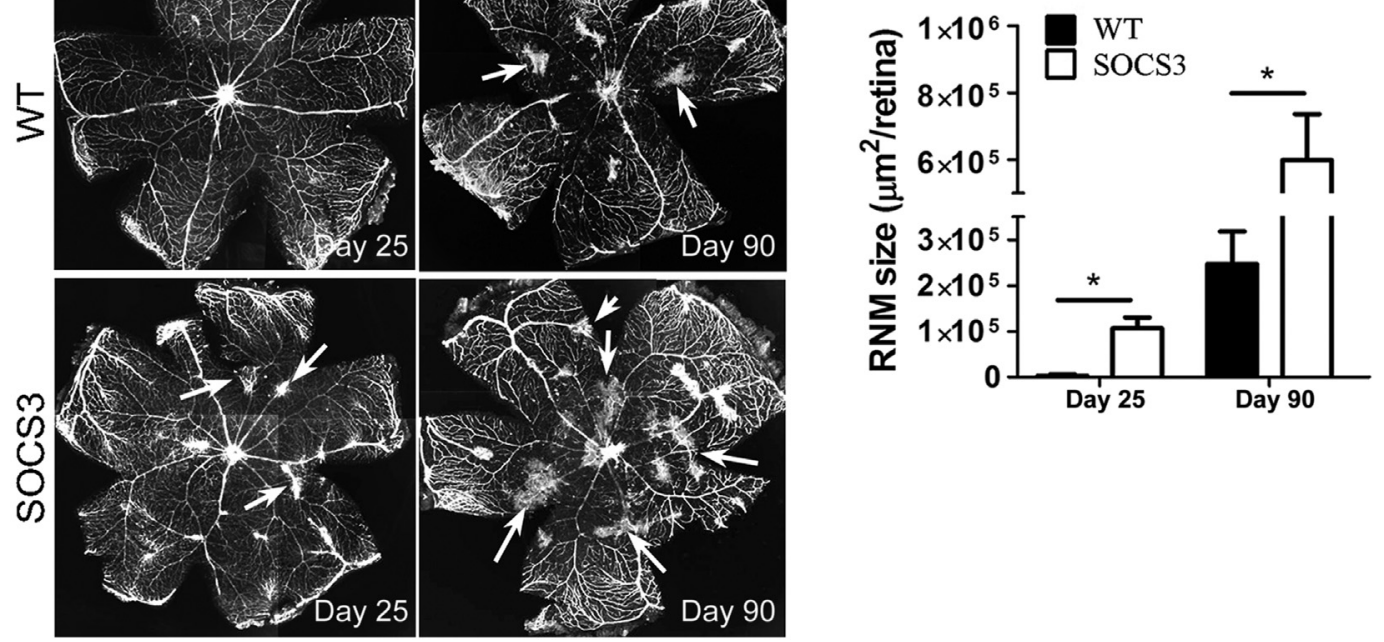

Figure 2 Retinal fibrovascular membrane in wild-type (WT) and myeloid cell-specific suppressor of cytokine signaling protein 3 (SOCS3)-deficient $\left(\right.$ LySM $^{\text {Cre/+}}{ }^{S O C S 3^{f / f l}}$ ) experimental autoimmune uveoretinitis (EAU) mice. EAU was induced in WT and LysM ${ }^{\text {Cre/ }+}$ SOCS3 ${ }^{f / f l}$ mice, and fluorescein angiography (FA) was conducted at different days post immunization (p.i.) (day 25, day 60, and day 90). A: Representative FA images from WT and LysM ${ }^{\text {Cre/ } /+}$ SOCS $3^{f / f l}$ mice on different days p.i. Arrows indicate the hyperfluorescent lesions. B: The number of hyperfluorescent lesions per eye in each group at different times. C: Confocal image from a day 60 p.i. WT EAU retina stained for collagen IV showing new blood vessels (arrows) and collagen deposition (asterisk) around a diseased venule. D: Confocal image from a retinal section from a day 90 p.i. WT EAU retina stained for collagen IV (green) and CD105 (red) showing multiple vessels (arrows) in retinal fibrovascular membrane. $\mathbf{E}$ and $\mathbf{F}$ : Retinal flat mounts from days 25 and 90 p.i., EAU mice were stained for collagen IV and imaged by confocal microscopy. E: Representative images of retinal flat mounts from WT and LysM ${ }^{C r e /+}$ SOCS3 ${ }^{f / f l}$ mice showing retinal vasculature and neovascular membrane (arrows). Images were taken from four quadrants of retina using $5 \times$ objective lens. F: The size of retinal neovascular membrane (RNM) in WT and $\mathrm{LySM}^{\mathrm{Cre} /+} \mathrm{SOCS} 3^{f / f l}$ mice at day $25 \mathrm{~s}$ and 90 p.i. Data are expressed as means \pm SEM (B and $\left.\mathbf{F}\right) . n=6$ to $8 .{ }^{*} P<0.05$ versus WT mice at the same time point. Scale bars: $500 \mu \mathrm{m}(\mathbf{A}) ; 50 \mu \mathrm{m}($ C) $; 25 \mu \mathrm{m}$ (D). Con, control. 
A

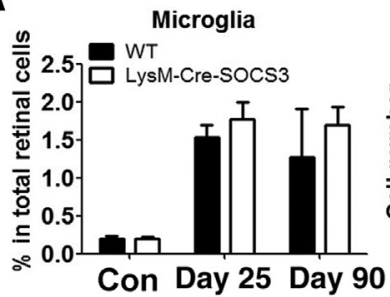

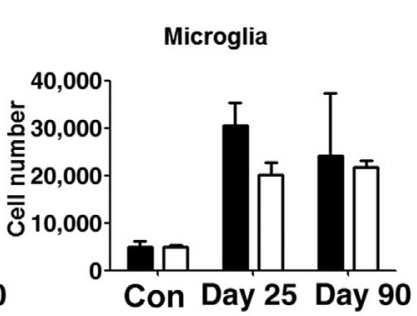

B

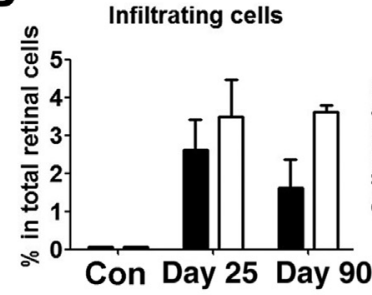

Infiltrating cells

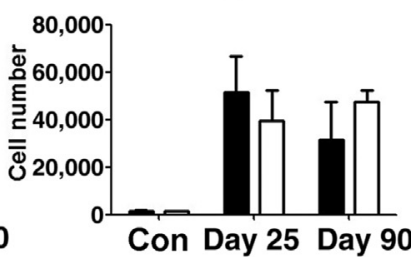

C

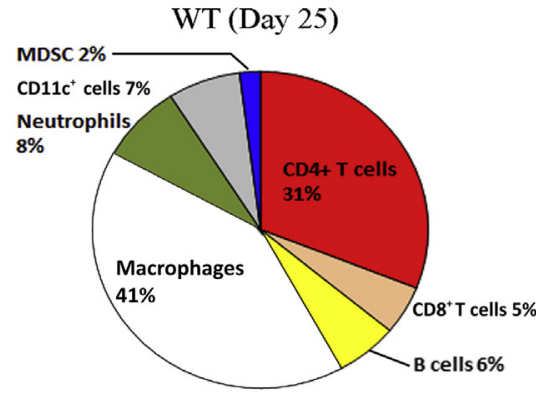

WT (Day 90)

D

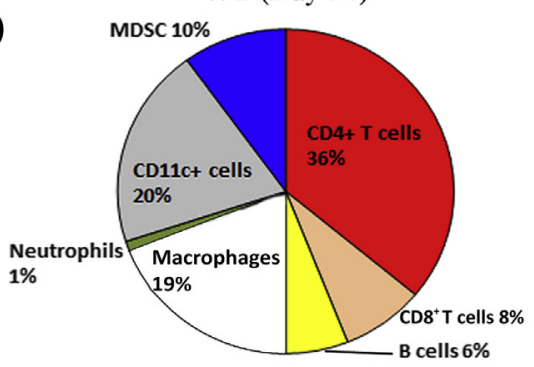

LysM-Cre-SOCS3 (Day 25)

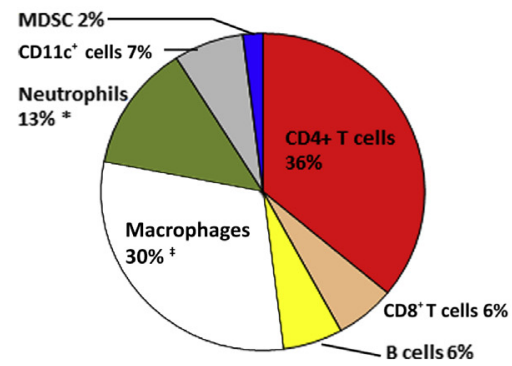

LysM-Cre-SOCS3 (Day 90)

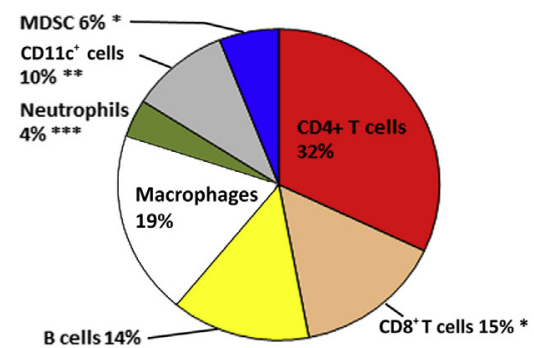

Figure 3 The constitution of immune cells in wild-type (WT) and myeloid cell-specific suppressor of cytokine signaling protein 3 (SOCS3)deficient (LysM ${ }^{\text {Cre/+}}{ }^{-} \mathrm{SOCS} 3^{f / / f l}$ ) experimental autoimmune uveoretinitis (EAU) retina. Retinas from days 25 and 90 post immunization (p.i.) in WT and SOCS3 knockout (KO) mice were collected. Single-cell suspension was prepared (Materials and Methods) and stained for different cell surface markers and analyzed by flow cytometry. A: The number and percentage of retinal microglia cells in different stages of EAU in WT and $\mathrm{LySM}^{\mathrm{Cre} /+} \mathrm{SOCS}^{\mathrm{fl} / f l}$ mice. B: The number and percentage of retinal infiltrating cells in different stages of EAU in WT and LysM $^{\text {Cre/t+}}$ SOCS3 ${ }^{f l / f l}$ mice. C and D: Pie charts showing the percentages of macrophages $\left(\mathrm{F} 4 / 80^{+}\right)$, neutrophils $\left(\mathrm{CD} 11^{+} \mathrm{Gr}-1^{+} \mathrm{Ly}_{6 \mathrm{G}}{ }^{+}\right)$, dendritic cells $\left(\mathrm{CD} 11 \mathrm{c}^{+}\right)$, myeloid-derived sup-

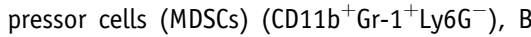
cells $\left(\mathrm{B}_{220^{+}}\right)$, and $\mathrm{CD} 4^{+}$and $\mathrm{CD} 8^{+}$cells in WT and SOCS3 KO EAU retinas at days 25 (C) and 90 (D) p.i. Data are expressed as means \pm SEM. $n=3$. ${ }^{*} P<0.05,{ }^{*} P<0.01$, and ${ }^{* *} P<0.001$ versus WT mice at the same time point. Con, control. collagen deposition and new blood vessels (Figure 2C). The new blood vessels were further confirmed by collagen IV and CD105 dual staining (Figure 2D). The results suggest the fibrovascular nature of the RNM. The LysM $^{C r e /+}{ }^{S O C S} 3^{f / f l}$ EAU mice developed the RNM earlier and it was larger compared with the WT EAU mice (Figure 2, C and D). The data suggest that deletion of SOCS3 in myeloid cells resulted in early onset and more severe retinal fibrovascular membrane in EAU.

\section{Increased Neutrophils in the Lys $\mathrm{M}^{\mathrm{Cre} /+} \mathrm{SOCS} 3^{f / f l}$ EAU Mice}

Flow cytometry analysis revealed no difference in the percentage of different subsets of leukocytes (CD4, CD8,

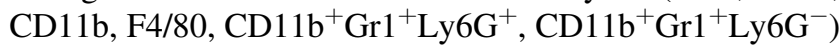
in the blood and spleen between nonimmunized WT and LysM $^{\text {Cre/ }}{ }_{\text {SOCS3 }}{ }^{\text {flfl }}$ mice (Supplemental Figure S3, A and $\mathrm{B}$ ). After induction of EAU, there was a reduction in CD4 and CD8 T-cell populations and an increase in CD11b, $\mathrm{CD}_{11} \mathrm{~b}^{+} \mathrm{Gr}^{+}{ }^{+} \mathrm{Ly}_{6 \mathrm{G}}{ }^{+}$(neutrophil), and $\mathrm{CD} 11 \mathrm{~b}^{+} \mathrm{Gr}^{+} \mathrm{Ly}^{+} \mathrm{G}^{-}$ MDSC at days 25 and 90 p.i. in the blood (Supplemental
Figure S3C) and spleen (data not shown) in both WT and $\mathrm{LysM}^{\mathrm{Cre} /+} \mathrm{SOCS} 3^{\text {fl/fl}}$ mice. However, significantly higher percentages of neutrophils and lower percentages of $\mathrm{F} 4 / 80^{+}$ macrophages were observed in $\mathrm{LysM}^{\mathrm{Cre} /+} \mathrm{SOCS}^{\text {fl/fl }}$ EAU mice at day 25 p.i. (Supplemental Figure S3C).

Retinal resident microglia are $\mathrm{CD} 45^{\text {int }} \mathrm{CD} 11 \mathrm{~b}^{+}$, and infiltrating leukocytes are CD45 ${ }^{\text {hi }} .{ }^{10}$ EAU increased the percentages and the absolute number of microglia and infiltrating leukocytes in both WT and $\mathrm{LysM}^{\mathrm{Cre} /+} \mathrm{SOCS} 3^{f / f l}$ mice (Figure 3, A and B). The percentages and absolute numbers of microglia and infiltrating leukocytes were comparable in WT and $\mathrm{LysM}^{\mathrm{Cr} /+}{ }^{\mathrm{SOCS}} 3^{f / f l}$ EAU mice. Further analysis of retinal infiltrating leukocyte subsets showed that the $\mathrm{LysM}^{\mathrm{Cr} /+} \mathrm{SOCS} 3^{f / f l}$ EAU mice contained more lymphocytes (T and B cells) and less myeloid-derived cells compared with WT EAU mice, particularly at day 90 p.i. (Figure 3, C and D). Within the myeloid-derived cells, higher percentages of neutrophils were observed in the LysM $^{\text {Cre/ }}{ }^{\text {SOCS3 }}{ }^{\text {flfl }}$ EAU retina at both day 25 and 90 p.i. (Figure 3, C and D). These results suggest that deletion of SOCS3 in myeloid cells shifts retinal immune infiltration toward lymphocytes and neutrophils in EAU. 
Inflammatory and Angiogenic Gene Expression in EAU Mouse Retina

Under noninflammatory condition, the $\mathrm{LysM}^{\mathrm{Cre} /+} \mathrm{SOCS} 3^{\text {fl/ft }}$ mouse retina expressed significantly higher levels of TNF- $\alpha$, inducible nitric oxide synthase (iNOS), GM-CSF, VEGF- $\alpha$, and Arg-1 compared with WT mouse retina (Figure 4A). The expression of IFN- $\gamma$, IL-17a, IL-10, and IL-6 was below detectable levels in both WT and $\mathrm{LysM}^{\mathrm{Cre} /+} \mathrm{SOCS} 3^{f / f l}$ mice. After EAU induction, the expression of iNOS, TNF- $\alpha$, IL- $1 \beta$, GM-CSF, IFN- $\gamma$, IL17a, IL-6, IL-10, CXCL2, and CCL2 was markedly increased at day 25 p.i. and remained at high levels throughout the study in both WT and $\mathrm{LysM}^{\mathrm{Cre} / \mathrm{S}} \mathrm{SOCS} 3^{\text {flf }}$ mice (Figure 4B). The $\mathrm{LysM}^{\mathrm{Cre} /+} \mathrm{SOCS}^{\text {fl/f }}$ EAU retina expressed significantly higher levels of TNF- $\alpha$, IL-1 $\beta$, GMCSF, IFN- $\gamma$, IL-6, CCL2, CXCL2, and VEGF- $\alpha$ compared with the WT EAU retina (Figure 4B). Importantly, the expression level of Arg-1 in the $\mathrm{LysM}^{\mathrm{Cre} /+} \mathrm{SOCS}^{\text {flffl}}$ EAU mouse was 49-fold higher than that in WT mouse retina at day 25 p.i. ( $685 \pm 218$ versus $14 \pm 2.7)$. Retinal wholemount staining showed that Arg-1 was expressed exclusively in infiltrating CD45 ${ }^{+}$cells (Figure $4, \mathrm{C}$ and D), and the percentage of Arg- $1^{+}$cells was significant higher in LysM $^{\mathrm{Cre} /+} \mathrm{SOCS}^{\mathrm{fl} / \mathrm{fl}}$ EAU retina $(35 \%)$ (Figure 4D) compared with WT EAU retina (18\%) (Figure 4C). These results suggest that the $\mathrm{LysM}^{\mathrm{Cre} / \mathrm{H}} \mathrm{SOCS} 3^{\mathrm{fl} / \mathrm{fl}}$ EAU retinas expressed higher levels of inflammatory cytokines and angiogenic growth factors.

\section{Effects of SOCS3 Deletion in BMDMs and Neutrophils}

Using a standard BMDM culture protocol, similar numbers of $\mathrm{F} 4 / 80^{+} \mathrm{CD} 11 \mathrm{~b}^{+}$cells were yielded from LysM ${ }^{\mathrm{Cre} /+} \mathrm{SOCS} 3^{\text {flff }}$ and SOCS3 $3^{f / f l}$ mice, suggesting that deletion of SOCS3 in myeloid lineage did not affect macrophage differentiation. Naïve SOCS3-deficient BMDMs expressed higher levels of IL-1 $\beta$, VEGF- $\alpha$, and Arg- 1 compared with WT cells (Figure 5A). After LPS/IFN- $\gamma$ stimulation, the expression of inflammatory genes, including TNFA, ILI $\beta$, iNOS, and IL6, was significantly increased in both $\mathrm{SOCS}^{f l / f l}$ and SOCS3deficient cells (data not shown). Interestingly, higher levels of IL10 mRNA were observed in SOCS3-deficient BMDMs (Figure 5B). IL-4 treatment increased the expression of IL-10, CCL2, VEGF, chitinase-like protein 3 (Ym-1), and Arg-1 in both $\mathrm{SOCS}^{f / f t}$ and SOCS3-deficient BMDMs (data not shown), although the expression of CCL2 and Arg-1 was significantly higher in SOCS3-deficient BMDMs compared with SOCS3 ${ }^{\text {flfl }}$ BMDMs (Figure 5C). Neutrophils from SOCS3-deficient mice expressed significantly higher levels of Arg-1, CCL2, and IL-6 compared with those from WT mice (Figure 5D). The oxidative burst and phagocytic activity were also higher in SOCS3-deficient neutrophils (Supplemental Figure S4).

SOCS3-deficient BMDMs produced higher levels of VEGF (under nonstimulatory conditions), IL-10 (after IFN-
r/LPS stimulation), and CCL2 (after IL-4 stimulation) compared with $\mathrm{SOCS}^{f / f t}$ BMDMs (Figure 5E). The production of TNF- $\alpha$, IL- 6 , IFN- $\gamma$, and nitric oxide did not differ between groups (Figure 5E).

\section{Effect of Arg Inhibition in Inflammation-Induced Retinal Angiogenesis}

To determine whether the early onset and severe RNM in LysM $^{\mathrm{Cre} /+} \mathrm{SOCS}^{\mathrm{flfl}}$ EAU retinas was due to enhanced Arg-1 expression, $\mathrm{LysM}^{\mathrm{Cre} /+} \mathrm{SOCS} 3^{f l / f}$ EAU mice were treated with an Arg inhibitor (ABH) from day 14 to day 59 p.i. Although the severity of inflammation remained unaffected (Figure 6A), retinal structure damage (Figure 6A) and angiogenesis (Figure 6B) were significantly reduced in ABHtreated mice compared with PBS controls.

The WT EAU mice develop RNM at day 60 p.i.; the mice were therefore treated with $\mathrm{ABH}$ from day 60 to 79 p.i. The treatment did not affect the severity of inflammation and structural damage (Figure 6C) but reduced the overall area of RNM (Figure 6D) and the number of localized hyperfluorescein lesions in FFA (Figure 6E). The results suggest that Arg activity may critically contribute to EAU-induced RNM.

\section{Discussion}

This study shows that the deletion of SOCS3 in myeloid cells resulted in severe retinal degeneration and an early onset of retinal fibrovascular membrane in EAU. It further shows that the $\mathrm{LysM}^{\mathrm{Cr} /+}{ }^{\mathrm{SOCS}} 3^{f / / f}$ EAU retina expressed higher levels of inflammatory cytokines (IL-1 $\beta$, TNF- $\alpha$, and IFN- $\gamma$ ) and angiogenic growth factors (VEGF and Arg-1) compared with WT EAU retina. Deletion of SOCS3 increased the expression of Arg-1 in macrophages and neutrophils. Importantly, it shows that the inhibition of Arg in EAU reduced retinal fibrovascular membrane without affecting the severity of inflammation. These results implicate a role for SOCS3 in regulating the phenotype and function of myeloid cells in retinal inflammation.

Retinal degeneration in EAU is primarily caused by antigen-specific T-cell-mediated photoreceptor death, ${ }^{27,28}$ although inflammatory mediators, such as TNF- $\alpha$, IL- $1 \beta$, reactive oxygen/nitric species (eg, nitric oxide) released by infiltrating neutrophils, and macrophages, also critically contribute to retinal cell death. ${ }^{29-31}$ The total number of retinal infiltrating cells was comparable between WT and $\mathrm{LysM}^{\mathrm{Cre} / \mathrm{SOCS}} 3^{f / f l}$ EAU mice, but the latter displayed more lymphocytes and neutrophils and fewer macrophages. Previous studies in $\mathrm{EAE}^{32}$ and arthritis ${ }^{33}$ also reported increased neutrophilic infiltration in $\mathrm{LysM}^{\mathrm{Cre} /+} \mathrm{SOCS}^{\mathrm{flff}}$ mice. Neutrophil-dominated EAU has been observed in the CCL2 or CCR2 knockout mice by us and others, ${ }^{7,10}$ although such inflammation did not cause more severe retinal degeneration compared with the macrophage-dominated EAU in WT mice. ${ }^{7,10,34}$ The results suggest that the phenotype of 
A

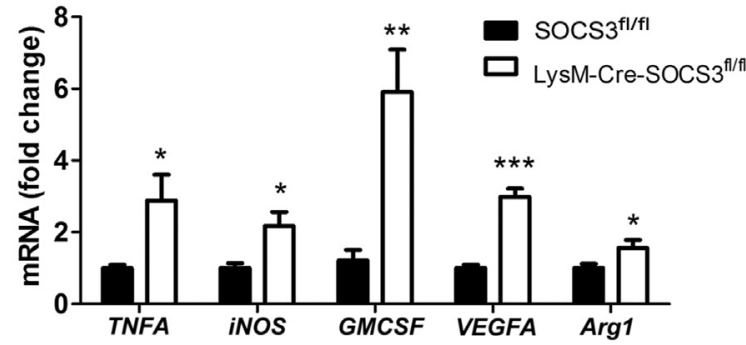

- SOCS3 $3^{f / f \mid}$

- - LysM-Cre-SOCS3

B
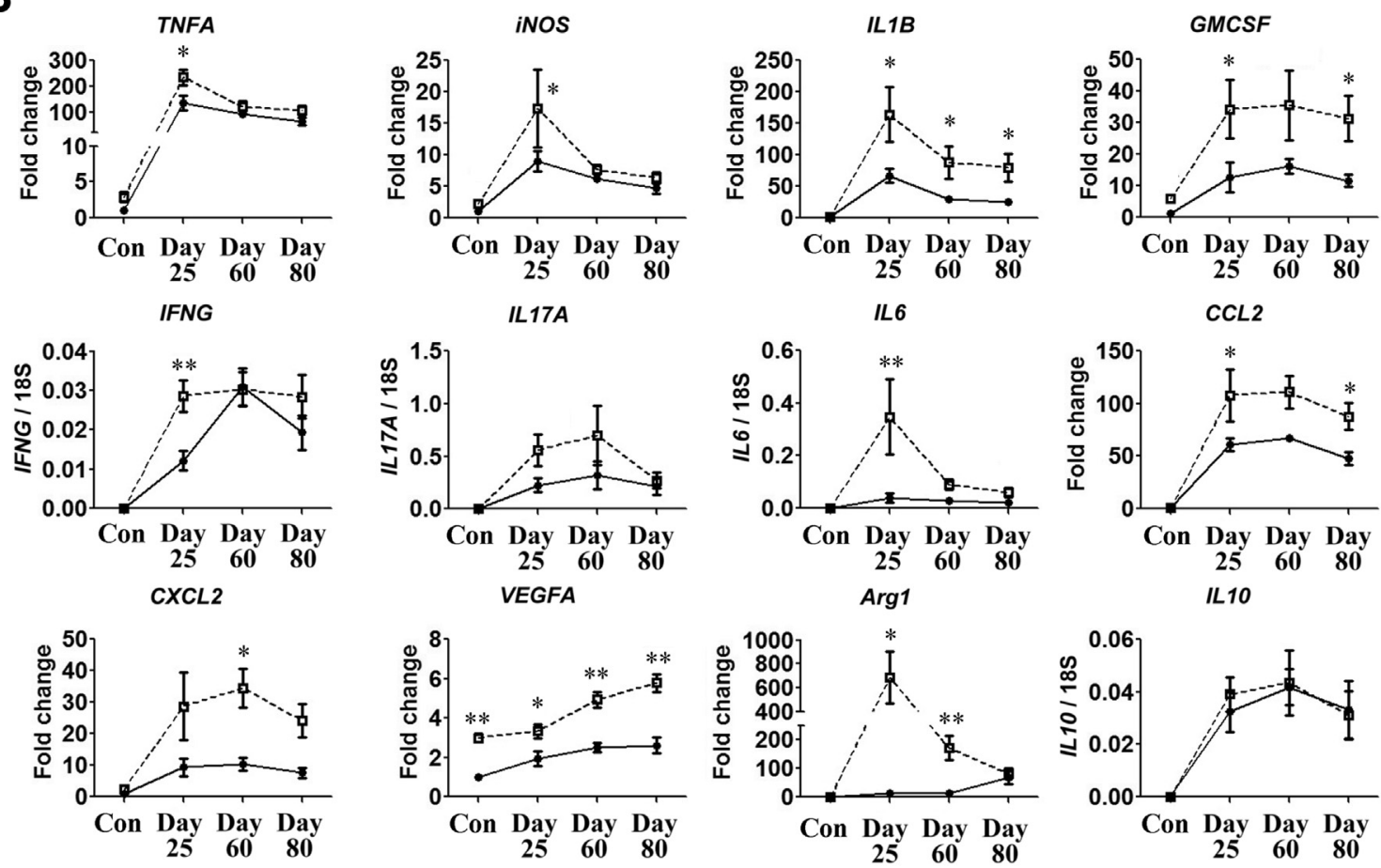

C

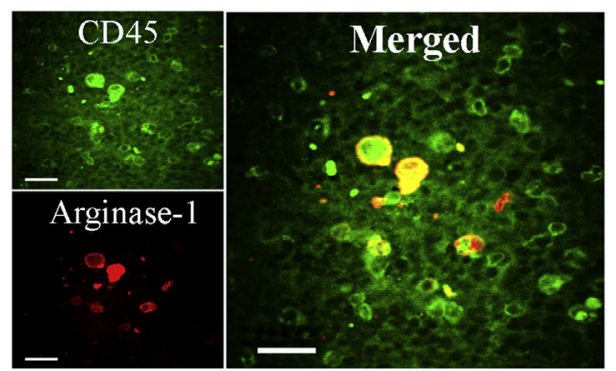

\section{D}

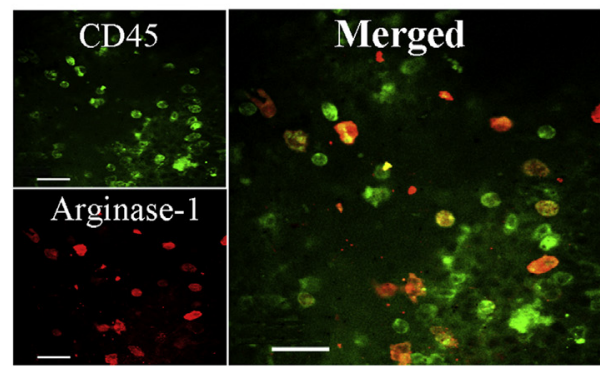

Figure 4 Inflammatory gene expression in the retina in wild-type (WT) and myeloid cell-specific suppressor of cytokine signaling protein 3 (SOCS3)-

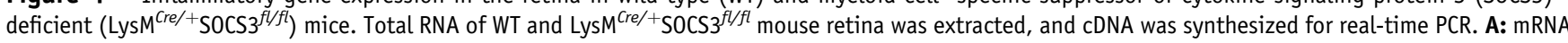
expression of the TNFA, iNOS (official name ISNYA1), GMCSF (official name CSF2), VEGFA, and Arg1 genes in normal WT and SOCS3 knockout (K0) mice. B: mRNA expression of TNFA, IL1B, iNOS, GMCSF, IFNG, IL17A, IL6, CCL2, CXCL2, VEGFA, IL10, and Arg1 genes at days 25, 60, and 80 of experimental autoimmune uveoretinitis (EAU) in WT and SOCS3 KO mice. The results shown are gene fold change compared with WT nonimmunized control retina. C and D: Retinal flat mounts from day 60 p.i. EAU of WT (C) and Lys $\mathrm{M}^{\mathrm{Cr} /+} \mathrm{SOCS}{ }^{f / f f}$ mice stained for CD45 (green) and arginase- 1 (red) and imaged by confocal microscopy. Data are expressed as means \pm SEM. $n=6$. ${ }^{*} P<0.05,{ }^{* *} P<0.01$, and ${ }^{* *} P<0.001$ versus SOCS3 K0 mouse retina at the same time point (two-way analysis of variance with Bonferroni posttests). Scale bars $=50 \mu \mathrm{m}$ (C and D). Con, control.

infiltrating neutrophils may determine the level of retinal damage. The GM-CSF signaling pathway critically controls neutrophil differentiation and activation and is negatively regulated by SOCS3. ${ }^{35}$ The LysM ${ }^{\text {Cre/t+}}$ SOCS3 $3^{\text {fl/f }}$ EAU retina expressed higher levels of GM-CSF, and neutrophils from these mice expressed more IL-6, CCL2, and Arg-1 and displayed higher levels of oxidative burst and increased phagocytosis compared with the cells from WT mice. SOCS3 
A

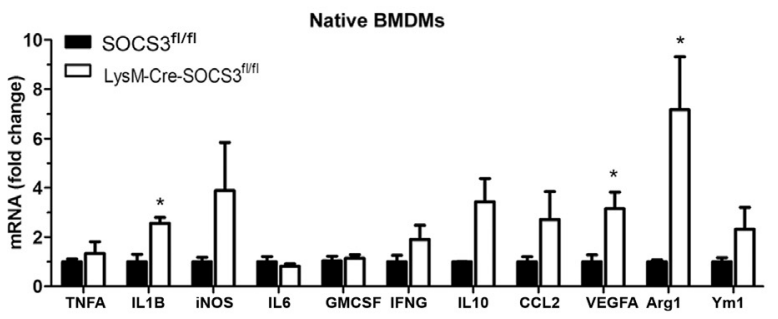

C

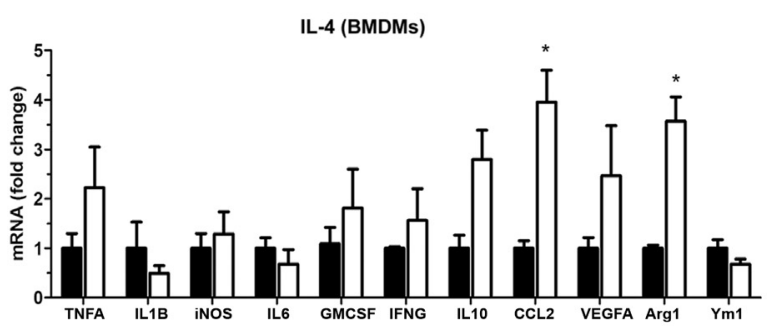

B

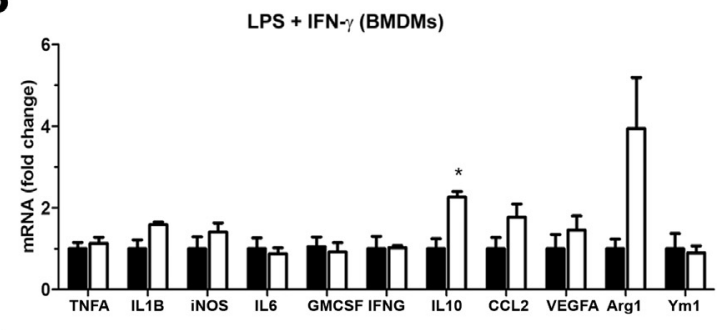

D

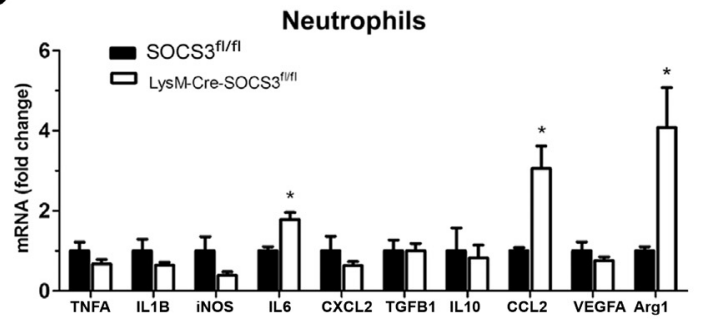

$\mathbf{E}$
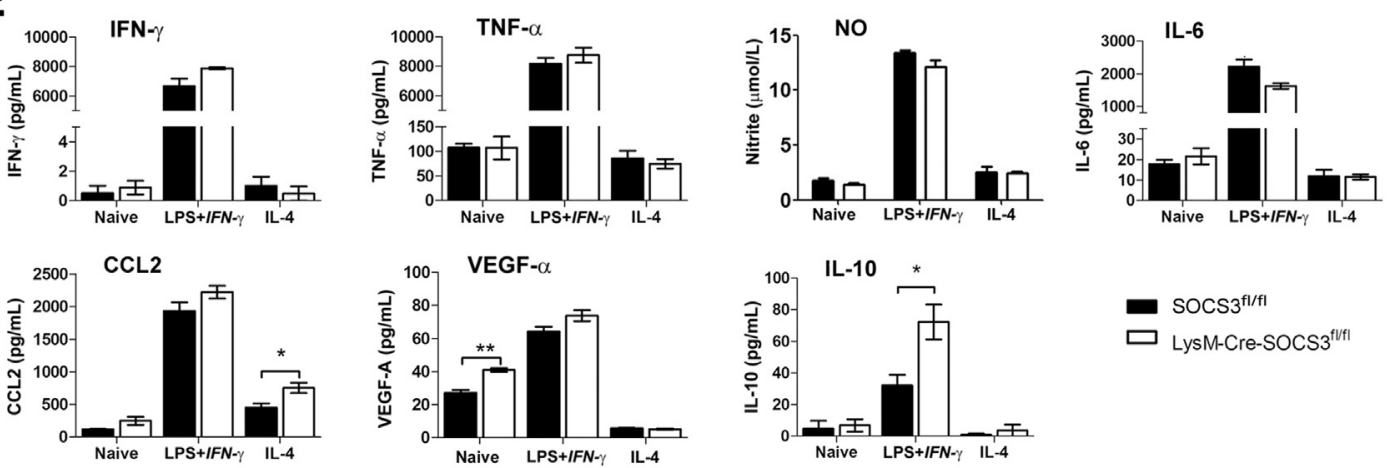

Figure 5 Immune gene expression and protein secretion in bone marrow-derived macrophages (BMDMs) and neutrophils from suppressor of cytokine signaling protein 3-deficient (SOCS3 ${ }^{f / f l}$ ) and myeloid cell-specific SOCS3-deficient (LysM ${ }^{\text {Cre/ }}+$ SOCS ${ }^{f l f l}$ ) mice. BMDMs were cultured from SOCS3 $3^{f / f l}$ and SOCS3 knockout (KO) mice, and neutrophils were isolated from bone marrow of these mice. Total RNA was extracted from the cells and cDNA was synthesized for real-time PCR. A-C: Immune gene expression in naïve nonpolarized M0 (A), lipopolysaccharide (LPS)/interferon (IFN)- $\gamma$ (B), or IL-4 (C) treated macrophages from SOCS $3^{f / f l}$ and SOCS3 KO mice. D: Immune gene expression in bone marrow-derived neutrophils from wild-type (WT) and SOCS3 KO mice. Data presented are gene fold-changes in cells from SOCS3 KO mice compared with that from SOCS3 ${ }^{f l f l}$ mice under the same treatment conditions. E: The protein levels in the supernatants of BMDMs from SOCS $3^{f l f l}$ and SOCS3 KO mice under different polarization conditions. Data are expressed as means \pm SEM. $n=3$ $(\mathbf{A}-\mathbf{D}) ; n=6(\mathbf{E}) .{ }^{*} P<0.05,{ }^{* *} P<0.01$ versus SOCS $3^{f / f l}$ mice (unpaired $t$-test). CCL2, chemokine (C-C motif) ligand $2 ;$ IFN- $\gamma$, interferon $\gamma ; \mathrm{N} 0$, nitric oxide; TNF- $\alpha$, tumor necrosis factor $\alpha$; VEGF- $\alpha$, vascular endothelial growth factor $\alpha$.

is known to negatively control macrophage phagocytosis, and SOCS3 knockdown increases macrophage phagocytic activity. ${ }^{36}$ Our results suggest that deletion of SOCS3 may lead to altered neutrophil/macrophage activation, which may contribute to increased retinal degeneration in $\mathrm{LysM}^{\text {Crel }}$ ${ }^{+} \mathrm{SOCS} 3{ }^{\text {fl/f }}$ EAU mice.

The higher percentages of infiltrating lymphocytes (CD4, $\mathrm{CD} 8$, and $\mathrm{B}$ cells) may also contribute to increased retinal degeneration in the $\mathrm{LysM}^{\mathrm{Cr} /+}{ }^{\mathrm{SOCS}} 3^{f / f l}$ EAU mice. T-cell activation in autoimmunity is induced by antigen-presenting cells (ie, DCs and macrophages), and SOCS3 is known to be critically involved in DC differentiation and functions. ${ }^{37,38}$ SOCS3 can regulate indoleamine 2,3-dioxygenase expression in DCs, ${ }^{39}$ which critically controls the balance between T-cell activation and tolerance. Overexpression of SOCS3 in DCs suppresses invariant natural killer T-cell activation in autoimmune arthritis. ${ }^{40}$ However, a previous study reported reduced potential to drive effector T-cell responses and increased induction of tolerogenic $\mathrm{T}$ cells by SOCS3deficient DCs, ${ }^{41}$ which does not support enhanced autoimmune pathology in the mice observed by us and others. How T-cell activation and migration in EAU are affected in $\mathrm{LysM}^{\mathrm{Cre} /+} \mathrm{SOCS}^{f / f l}$ mice warrants further investigation.

Macrophages are known to play an important role in retinal degeneration and angiogenesis. Although the percentage of infiltrating macrophages was lower in $\mathrm{LysM}^{\mathrm{Cre} /+} \mathrm{SOCS}^{\mathrm{flfl}}$ EAU mice compared with that in WT EAU mice, they may be more angioegenic. Macrophage polarization and function are regulated by SOCS proteins, particularly SOCS1 and SOCS3. ${ }^{20,21}$ For example, SOCS3 negatively regulates GMCSF-induced CCL2, Arg-1, and matrix metallopeptidase 12 expression in BMDMs. ${ }^{35,42}$ The higher levels of GM-CSF in 
A

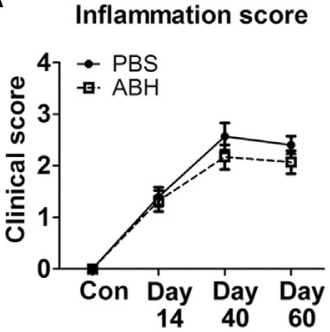

C

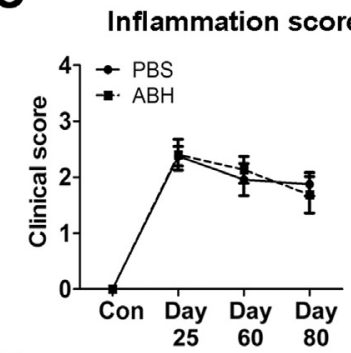

Structural damage score

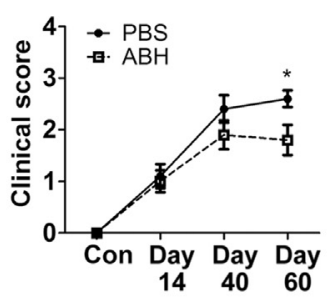

B
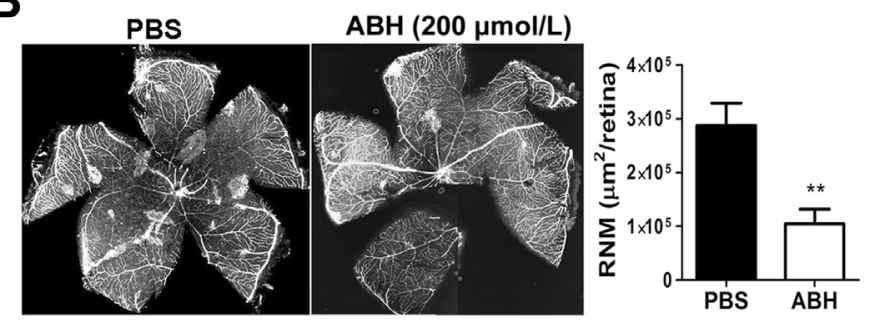

E

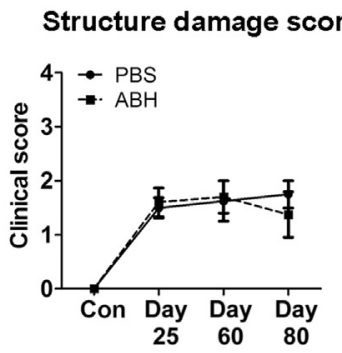

D
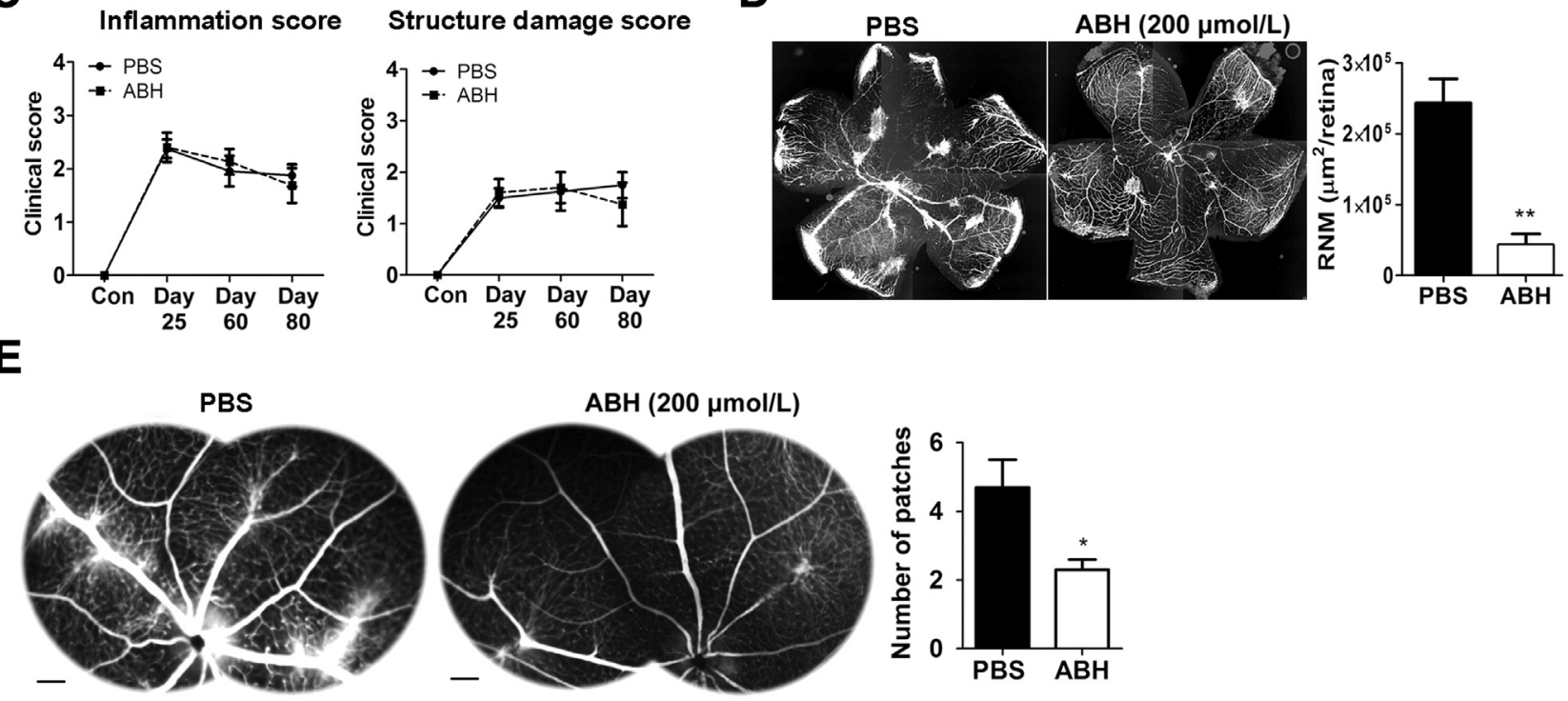

Figure 6 The effects of amino-2-borono-6-hexanoic ( $\mathrm{ABH}$ ) on experimental autoimmune uveoretinitis (EAU)-induced retinal angiogenesis in wild-type

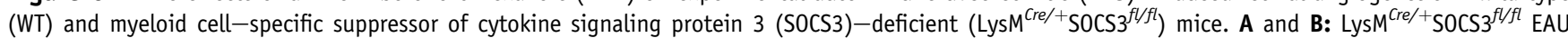
mice were treated intraperitoneally with $200 \mu \mathrm{M} \mathrm{ABH}$ or phosphate-buffered saline (PBS) once daily from days 14060 post immunization (p.i.). A: Clinical score of inflammation and structural damage at days 14, 40, and 60 p.i. B: Representative confocal images of retinal flat mounts from day 60 p.i. and the number of retinal neovascular membranes (RNMs) in PBS- and ABH-treated SOCS3 knockout (KO) mice. Images were taken from quadrants of the retina using $5 \times$ objective lens. C-E: WT EAU mice were treated intraperitoneally with $200 \mu \mathrm{M} \mathrm{ABH}$ or PBS once daily from day 60 to day $79 \mathrm{p.i}$. C: Clinical score of inflammation and structural damage were evaluated at days 25, 60, and 80 p.i. D: Representative confocal images of retinal flat mounts from day p.i. and the number of RNMs in PBS- and ABH-treated EAU KO mice. Images were taken from quadrants of the retina using $5 \times$ objective lens. E: Fluorescent angiography showing hyperfluorescent lesions in PBS- and ABH-treated EAU mice and the mean number of hyperfluorescent lesions. Data are expressed as means \pm SEM. $n=5$ to 6 mice. ${ }^{*} P<0.05,{ }^{*} P<0.01$ versus PBS-treated group. Scale bars $=500 \mu \mathrm{m}(\mathbf{E})$. Con, control.

$\mathrm{LysM}^{\mathrm{Cre/+}} \mathrm{SOCS} 3^{\text {flfl }}$ mouse retina may induce CCL2 and Arg-1 expression in macrophages.

The BMDMs from $\mathrm{LysM}^{\mathrm{Cre} /+} \mathrm{SOCS} 3^{\text {fl/f }}$ mice appear to have an anti-inflammatory or wound healing phenotype evidenced by higher levels of IL-10, VEGF, and Arg-1 expression. This result is in line with previous SOCS3 knockdown studies ${ }^{43,44}$ and a study in tumor metastasis in the $\mathrm{LysM}^{\mathrm{Cre} /+}$ SOCS $3^{f / f}$ mouse. ${ }^{45}$ However, other studies have found that deletion of SOCS3 in myeloid cells promoted M1 macrophage differentiation, including increased IL- $1 \beta$, TNF- $\alpha$, iNOS, and decreased IL-10 expression, ${ }^{46,47}$ although the expression of Arg-1 and VEGF was not investigated in those studies. What causes the discrepancy remains unknown. The in vitro observation in BMDMs matches the neutrophil data and the EAU retina gene expression profile.

The development of RNM in EAU is related to the shift of infiltrating macrophages from $\mathrm{CD}^{+} 8^{+}$to Arg- $1^{+}$phenotype. ${ }^{7}$ At day 25 p.i., the expression of Argl mRNA in the
$\mathrm{LysM}^{\mathrm{Cre} / \mathrm{SOCS}}{ }^{\text {flfl }}$ mouse retina was substantially higher than that in the WT mouse retina, and treatment of EAU with an $\mathrm{Arg}$ inhibitor (ABH) suppressed retinal angiogenesis without affecting the severity of inflammation. Macrophages and neutrophils from $\mathrm{LysM}^{\mathrm{Cre} /+} \mathrm{SOCS}^{f / f l}$ mice expressed significantly higher levels of Arg-1 and VEGF compared with those from WT mice. Arg catalyzes the conversion of arginine to ornithine, a precursor of polyamines and collagen, thus contributing to the production of extracellular matrix that supports angiogenesis. ${ }^{48} \mathrm{Arg}$ is known to play an important role in regulating inflammation and is involved in vascular complications of retinal disease, including diabetic retinopathy $^{49,50}$ and choroidal neovascularization. ${ }^{51}$ Our results highlight the role of Arg-1 as an important angiogenic mediator under inflammatory conditions.

The early onset of RNM in the LysM ${ }^{C r e /+} \mathrm{SOCS}^{f / f l}$ mice is in line with the previous observation in the laser-induced choroidal neovascularization in these mice, ${ }^{52}$ where a link 
between signal transducer and activator of transcription 3 (STAT3) activation in circulating immune cells and neovascular age-related macular degeneration was reported. The role of the SOCS3-STAT3 pathway in retinal inflammation and angiogenesis has been observed in a number of studies. Sun et $\mathrm{al}^{53}$ found that SOCS3 in retinal neurons and glial cells suppressed VEGF signaling to prevent pathologic neovascular growth in mouse model of oxygen-induced retinopathy. Ozawa et $\mathrm{al}^{54}$ reported enhanced retinal inflammation and photoreceptor degeneration in retina-specific SOCS3 knockout mice after LPS stimulation. Further understanding the role of the SOCS3-STAT3 pathway in retinal health and disease may uncover novel target for therapy.

In summary, our study suggests that SOCS3 critically controls the phenotype and functions of macrophages and neutrophils under inflammatory conditions. In the absence of SOCS3, macrophages and neutrophils express higher levels of Arg-1, CCL2, IL-6, and VEGF and promote angiogenesis. SOCS3 deficiency also enhances phagocytosis and oxidative bursts in neutrophils, which may contribute to exacerbated retinal degeneration in EAU. Targeting SOCS3 may be a novel approach to control inflammation and its related angiogenesis.

\section{Acknowledgments}

M.C., J.Z., I.H.A.A., S.M., and A.L. conducted the experiment; A.K. provided LysM ${ }^{\mathrm{Cre} /+} \mathrm{SOCS} 3^{f l / f}$ mice; M.C. and H.X. designed the experiments, supervised the work, and analyzed the data; J.Z., M.C., and H.X. wrote the manuscript; and all the authors have read the manuscript and approved the submission.

\section{Supplemental Data}

Supplemental material for this article can be found at https://doi.org/10.1016/j.ajpath.2017.12.021.

\section{References}

1. Marrelli A, Cipriani P, Liakouli V, Carubbi F, Perricone C, Perricone R, Giacomelli R: Angiogenesis in rheumatoid arthritis: a disease specific process or a common response to chronic inflammation? Autoimmun Rev 2011, 10:595-598

2. Costa C, Incio J, Soares R: Angiogenesis and chronic inflammation: cause or consequence? Angiogenesis 2007, 10:149-166

3. Majno G: Chronic inflammation: links with angiogenesis and wound healing. Am J Pathol 1998, 153:1035-1039

4. Kim LA, D'Amore PA: A brief history of anti-VEGF for the treatment of ocular angiogenesis. Am J Pathol 2012, 181:376-379

5. Campa C, Harding SP: Anti-VEGF compounds in the treatment of neovascular age related macular degeneration. Curr Drug Targets 2011, 12:173-181

6. Grothey A, Galanis E: Targeting angiogenesis: progress with antiVEGF treatment with large molecules. Nat Rev Clin Oncol 2009, 6: 507-518

7. Chen M, Copland DA, Zhao J, Liu J, Forrester JV, Dick AD, Xu H: Persistent inflammation subverts thrombospondin-1-induced regulation of retinal angiogenesis and is driven by CCR2 ligation. Am J Pathol 2012, 180:235-245

8. Dhingra N, Kelly S, Majid MA, Bailey CB, Dick AD: Inflammatory choroidal neovascular membrane in posterior uveitis-pathogenesis and treatment. Indian J Ophthalmol 2010, 58:3-10

9. Yannuzzi LA, Negrao S, Iida T, Carvalho C, Rodriguez-Coleman H, Slakter J, Freund KB, Sorenson J, Orlock D, Borodoker N: Retinal angiomatous proliferation in age-related macular degeneration. Retina 2001, 21:416-434

10. Zhao J, Chen M, Xu H: Experimental autoimmune uveoretinitis (EAU)related tissue damage and angiogenesis is reduced in CCL2(-)/(-)CX(3) CR1gfp/gfp mice. Invest Ophthalmol Vis Sci 2014, 55:7572-7582

11. Chen M, Zhao J, Luo C, Pandi SP, Penalva RG, Fitzgerald DC, Xu H: Para-inflammation-mediated retinal recruitment of bone marrowderived myeloid cells following whole-body irradiation is CCL2 dependent. Glia 2012, 60:833-842

12. O'Shea JJ, Holland SM, Staudt LM: JAKs and STATs in immunity, immunodeficiency, and cancer. N Engl J Med 2013, 368:161-170

13. Miklossy G, Hilliard TS, Turkson J: Therapeutic modulators of STAT signalling for human diseases. Nat Rev Drug Discov 2013, 12 : 611-629

14. Chen Z, Han ZC: STAT3: a critical transcription activator in angiogenesis. Med Res Rev 2008, 28:185-200

15. Lu W, Chen H, Yel F, Wang F, Xie X: VEGF induces phosphorylation of STAT3 through binding VEGFR2 in ovarian carcinoma cells in vitro. Eur J Gynaecol Oncol 2006, 27:363-369

16. Alexander WS, Starr R, Metcalf D, Nicholson SE, Farley A, Elefanty AG, Brysha M, Kile BT, Richardson R, Baca M, Zhang JG, Willson TA, Viney EM, Sprigg NS, Rakar S, Corbin J, Mifsud S, DiRago L, Cary D, Nicola NA, Hilton DJ: Suppressors of cytokine signaling (SOCS): negative regulators of signal transduction. J Leukoc Biol 1999, 66:588-592

17. Yoshimura A, Yasukawa H: JAK's SOCS: a mechanism of inhibition. Immunity 2012, 36:157-159

18. Yoshimura A, Suzuki M, Sakaguchi R, Hanada T, Yasukawa H: SOCS, inflammation, and autoimmunity. Front Immunol 2012, 3:20

19. Carow B, Rottenberg ME: SOCS3, a major regulator of infection and inflammation. Front Immunol 2014, 5:58

20. Wilson HM: SOCS proteins in macrophage polarization and function. Front Immunol 2014, 5:357

21. McCormick SM, Heller NM: Regulation of macrophage, dendritic cell, and microglial phenotype and function by the SOCS proteins. Front Immunol 2015, 6:549

22. Avichezer D, Silver PB, Chan CC, Wiggert B, Caspi RR: Identification of a new epitope of human IRBP that induces autoimmune uveoretinitis in mice of the $\mathrm{H}-2 \mathrm{~b}$ haplotype. Invest Ophthalmol Vis Sci 2000, 41:127-131

23. Xu H, Manivannan A, Crane I, Dawson R, Liversidge J: Critical but divergent roles for CD62L and CD44 in directing blood monocyte trafficking in vivo during inflammation. Blood 2008, 112:1166-1174

24. Xu H, Koch P, Chen M, Lau A, Reid DM, Forrester JV: A clinical grading system for retinal inflammation in the chronic model of experimental autoimmune uveoretinitis using digital fundus images. Exp Eye Res 2008, 87:319-326

25. Dick AD, Cheng YF, Liversidge J, Forrester JV: Intranasal administration of retinal antigens suppresses retinal antigen-induced experimental autoimmune uveoretinitis. Immunology 1994, 82: 625-631

26. Luo C, Chen M, Madden A, Xu H: Expression of complement components and regulators by different subtypes of bone marrowderived macrophages. Inflammation 2012, 35:1448-1461

27. Caspi RR, Roberge FG, Chan CC, Wiggert B, Chader GJ, Rozenszajn LA, Lando Z, Nussenblatt RB: A new model of autoimmune disease: experimental autoimmune uveoretinitis induced in mice with two different retinal antigens. J Immunol 1988, 140: $1490-1495$ 
28. Liversidge J, Forrester JV: Experimental autoimmune uveitis (EAU): immunophenotypic analysis of inflammatory cells in chorio retinal lesions. Curr Eye Res 1988, 7:1231-1241

29. Forrester JV, Liversidge J, Dua HS, Dick A, Harper F, McMenamin PG: Experimental autoimmune uveoretinitis: a model system for immunointervention: a review. Curr Eye Res 1992, 11 Suppl:33-40

30. Dick AD, Ford AL, Forrester JV, Sedgwick JD: Flow cytometric identification of a minority population of MHC class II positive cells in the normal rat retina distinct from CD45lowCD11b/c+CD4low parenchymal microglia. Br J Ophthalmol 1995, 79:834-840

31. Dick AD, Kreutzer B, Laliotou B, Forrester JV: Phenotypic analysis of retinal leukocyte infiltration during combined cyclosporin A and nasal antigen administration of retinal antigens: delay and inhibition of macrophage and granulocyte infiltration. Ocul Immunol Inflamm 1997, 5:129-140

32. Qin $\mathrm{H}$, Yeh WI, De Sarno P, Holdbrooks AT, Liu Y, Muldowney MT, Reynolds SL, Yanagisawa LL, Fox TH 3rd, Park K, Harrington LE, Raman C, Benveniste EN: Signal transducer and activator of transcription-3/suppressor of cytokine signaling-3 (STAT3/SOCS3) axis in myeloid cells regulates neuroinflammation. Proc Natl Acad Sci U S A 2012, 109:5004-5009

33. Wong PK, Egan PJ, Croker BA, O’Donnell K, Sims NA, Drake S, Kiu H, McManus EJ, Alexander WS, Roberts AW, Wicks IP: SOCS3 negatively regulates innate and adaptive immune mechanisms in acute IL-1-dependent inflammatory arthritis. J Clin Invest 2006, 116: $1571-1581$

34. Sonoda KH, Yoshimura T, Egashira K, Charo IF, Ishibashi T: Neutrophil-dominant experimental autoimmune uveitis in CCchemokine receptor 2 knockout mice. Acta Ophthalmol 2011, 89: e180-e188

35. Tortorella C, Simone O, Piazzolla G, Stella I, Antonaci S: Age-related impairment of GM-CSF-induced signalling in neutrophils: role of SHP-1 and SOCS proteins. Ageing Res Rev 2007, 6:81-93

36. Gordon P, Okai B, Hoare JI, Erwig LP, Wilson HM: SOCS3 is a modulator of human macrophage phagocytosis. J Leukoc Biol 2016 , 100:771-780

37. Dimitriou ID, Clemenza L, Scotter AJ, Chen G, Guerra FM, Rottapel R: Putting out the fire: coordinated suppression of the innate and adaptive immune systems by SOCS1 and SOCS3 proteins. Immunol Rev 2008, 224:265-283

38. Liu X, Qu X, Chen Y, Liao L, Cheng K, Shao C, Zenke M, Keating A, Zhao RC: Mesenchymal stem/stromal cells induce the generation of novel IL-10-dependent regulatory dendritic cells by SOCS3 activation. J Immunol 2012, 189:1182-1192

39. Orabona C, Pallotta MT, Volpi C, Fallarino F, Vacca C, Bianchi R, Belladonna ML, Fioretti MC, Grohmann U, Puccetti P: SOCS3 drives proteasomal degradation of indoleamine 2,3-dioxygenase (IDO) and antagonizes IDO-dependent tolerogenesis. Proc Natl Acad Sci U S A 2008, 105:20828-20833

40. Veenbergen S, Bennink MB, Affandi AJ, Bessis N, Biton J, Arntz OJ, van den Berg WB, van de Loo FA: A pivotal role for antigenpresenting cells overexpressing SOCS3 in controlling invariant NKT cell responses during collagen-induced arthritis. Ann Rheum Dis 2011, 70:2167-2175
41. Matsumura Y, Kobayashi T, Ichiyama K, Yoshida R, Hashimoto M, Takimoto T, Tanaka K, Chinen T, Shichita T, Wyss-Coray T, Sato K, Yoshimura A: Selective expansion of foxp3-positive regulatory T cells and immunosuppression by suppressors of cytokine signaling 3-deficient dendritic cells. J Immunol 2007, 179:2170-2179

42. Jost MM, Ninci E, Meder B, Kempf C, Van Royen N, Hua J, Berger B, Hoefer I, Modolell M, Buschmann I: Divergent effects of GM-CSF and TGFbeta1 on bone marrow-derived macrophage arginase-1 activity, MCP-1 expression, and matrix metalloproteinase-12: a potential role during arteriogenesis. FASEB J 2003, 17:2281-2283

43. Liu Y, Stewart KN, Bishop E, Marek CJ, Kluth DC, Rees AJ, Wilson HM: Unique expression of suppressor of cytokine signaling 3 is essential for classical macrophage activation in rodents in vitro and in vivo. J Immunol 2008, 180:6270-6278

44. Arnold CE, Whyte CS, Gordon P, Barker RN, Rees AJ, Wilson HM: A critical role for suppressor of cytokine signalling 3 in promoting M1 macrophage activation and function in vitro and in vivo. Immunology 2014, 141:96-110

45. Hiwatashi K, Tamiya T, Hasegawa E, Fukaya T, Hashimoto M, Kakoi K, Kashiwagi I, Kimura A, Inoue N, Morita R, Yasukawa H, Yoshimura A: Suppression of SOCS3 in macrophages prevents cancer metastasis by modifying macrophage phase and MCP2/CCL8 induction. Cancer Lett 2011, 308:172-180

46. Qin H, Holdbrooks AT, Liu Y, Reynolds SL, Yanagisawa LL, Benveniste EN: SOCS3 deficiency promotes M1 macrophage polarization and inflammation. J Immunol 2012, 189:3439-3448

47. Yan C, Ward PA, Wang X, Gao H: Myeloid depletion of SOCS3 enhances LPS-induced acute lung injury through CCAAT/enhancer binding protein delta pathway. FASEB J 2013, 27:2967-2976

48. Durante W: Role of arginase in vessel wall remodeling. Front Immunol 2013, 4:111

49. Patel C, Rojas M, Narayanan SP, Zhang W, Xu Z, Lemtalsi T, Jittiporn K, Caldwell RW, Caldwell RB: Arginase as a mediator of diabetic retinopathy. Front Immunol 2013, 4:173

50. Narayanan SP, Rojas M, Suwanpradid J, Toque HA, Caldwell RW, Caldwell RB: Arginase in retinopathy. Prog Retin Eye Res 2013, 36 : $260-280$

51. Liu J, Copland DA, Horie S, Wu WK, Chen M, Xu Y, Paul Morgan B, Mack M, Xu H, Nicholson LB, Dick AD: Myeloid cells expressing VEGF and arginase-1 following uptake of damaged retinal pigment epithelium suggests potential mechanism that drives the onset of choroidal angiogenesis in mice. PLoS One 2013, 8:e72935

52. Chen M, Lechner J, Zhao J, Toth L, Hogg R, Silvestri G, Kissenpfennig A, Chakravarthy $\mathrm{U}, \mathrm{Xu} \mathrm{H}$ : STAT3 activation in circulating monocytes contributes to neovascular age-related macular degeneration. Curr Mol Med 2016, 16:412-423

53. Sun Y, Ju M, Lin Z, Fredrick TW, Evans LP, Tian KT, Saba NJ, Morss PC, Pu WT, Chen J, Stahl A, Joyal JS, Smith LE: SOCS3 in retinal neurons and glial cells suppresses VEGF signaling to prevent pathological neovascular growth. Sci Signal 2015, 8:ra94

54. Ozawa Y, Nakao K, Kurihara T, Shimazaki T, Shimmura S, Ishida S, Yoshimura A, Tsubota K, Okano H: Roles of STAT3/SOCS3 pathway in regulating the visual function and ubiquitin-proteasomedependent degradation of rhodopsin during retinal inflammation. $\mathrm{J}$ Biol Chem 2008, 283:24561-24570 